ISSN: 0514-7336 — ISSN electrónico: 2386-3943

DOI: https://doi.org/10.14201/zephyrus202085139162

\title{
EL YACIMIENTO SUBACUÁTICO DE LAS AMOLADERAS, CABO DE PALOS (CARTAGENA). NUEVOS ENFOQUES ARQUEOMÉTRICOS
}

\section{The underwater site of Las Amoladeras, Cabo de Palos (Cartagena). New archaeometric approaches}

\author{
Alejandro G. Sinner*, David Martínez-Chico** y Marco Ferrante*** \\ * Dept. of Greek and Roman Studies, University of Victoria. 3800 Finnerty Road (Ring Road), Clearihue Bldg. \\ B423.Victoria. Canadá.Correo-e: agsinner@uvic.ca. ID ORCID: https://orcid.org/0000-0002-5816-5794 \\ ** Dpto. de Prehistoria, Arqueología e H. a Antigua. Facultad de Geografía e Historia. Avda. Blasco Ibánez, 28. \\ 46010 Valencia. Correo-e: david_ele@live.com. ID ORCID: https://orcid.org/0000-0001-9907-3020 \\ *** Trace Technologies. Via Ignazio Silone, 6.64015 Nereto. Italia. Correo-e: info@trace-rc.com. ID ORCID: https:// \\ orcid.org/0000-0003-2398-7576
}

Recepción: 17/10/2019; Revisión: 04/03/2020; Aceptación: 20/04/2020

Resumen: El objetivo de este artículo es reinterpretar un conocido yacimiento subacuático en Las Amoladeras, situado en La Manga del Mar Menor, cerca de Cabo de Palos. Para ello, tras llevar a cabo una revisión historiográfica, se han estudiado, contextualizado y realizado análisis isotópicos de algunos de los materiales más interesantes del yacimiento, así como de un plomo monetiforme del mismo tipo que los hallados en Las Amoladeras y cuya circulación se atestigua en las Islas Baleares. Los análisis de isótopos de plomo efectuados sobre los materiales permiten determinar el origen del mineral de los dos primeros objetos en Cartagena-Mazarrón y Sierra Morena respectivamente, mientras que para la fabricación del plomo monetiforme parece haberse utilizado una mezcla de metal. Partiendo de lo anterior, interpretamos el yacimiento como los restos de un pecio que debe fecharse alrededor del 50-30 a. C., y que transportaba un cargamento formado en parte, si no casi exclusivamente, por objetos metálicos, principalmente plomo, seguramente para ser vendido y reciclado. El yacimiento de Las Amoladeras debe, por lo tanto, enmarcarse en un marco histórico y económico muy concreto: el de la comercialización y reutilización del plomo en la Hispania tardorrepublicana.

Palabras clave: Carthago Nova; Pollentia; comercio; isótopos; pecio; plomo; minería.

AвSTRACT: The aim of this article is to reinterpret a well-known underwater archaeological site located at Las Amoladeras, in La Manga del Mar Menor, near Cabo de Palos. For this purpose, after a historiographical review, we have studied, contextualized and undertaken isotopic analyses of some of the most interesting material from this archaeological site, as well as a plomo monetiforme (coin-like lead token) of the same type as those recovered at Las Amoladeras and the ones that circulated in the Balearic Islands. The lead isotope analyses carried out on the afore-mentioned artefacts allow us to determine the source of the lead used in the first two objects as Cartagena-Mazarrón and the Sierra Morena respectively. However, the lead used in the manufacture of the plomo monetiforme seems to reflect a mixture of metals. Based on all the above, we interpret this site as the remains of a shipwreck dating from 50-30 вс that was carrying a cargo composed in part, if not almost exclusively, of metallic items, mostly lead objects, probably to be sold and recycled. Las Amoladeras can therefore be contextualized in a very specific historical and economic framework: that of the commercialization and reuse of the lead in late Republican Hispania.

Key words: Carthago Nova; Pollentia; trade; isotopes; shipwreck; lead; mining. 


\section{Introducción ${ }^{1}$}

La Región de Murcia es una de las zonas del litoral peninsular donde se ha hallado un mayor número de yacimientos arqueológicos subacuáticos. Como ya apuntó Pinedo (1996: 59-62), esto se debe, entre otras cosas, a la importancia económica de la zona en época antigua (riqueza metalífera, producción agrícola, salinas y pesquerías, entre otros muchos recursos); a los abruptos relieves de sus costas que sirvieron como puertos y refugios naturales, $y$, finalmente, a la tradición subacuática tanto deportiva como científica que ha desarrollado históricamente esta comunidad autónoma (Jáuregui y Gil-Delgado, 1948). Es en este contexto en el que hemos de ubicar Las Amoladeras. Se trata de un yacimiento situado al frente de su playa homónima, perteneciente a La Manga del Mar Menor, muy cerca de Cabo de Palos (Fig. 1). Toda la zona se caracteriza por poseer un notable fondo de arena y algas, cuya profundidad oscila entre los 3 y $6 \mathrm{~m}$. Este espacio fue habitado ya en época calcolítica, como así lo demuestra el poblado costero ubicado al comienzo de La Manga (García del Toro, 1997-1998).

La irregular morfología del terreno ha sido el principal impedimento para que se lleve a cabo una delimitación sistemática del yacimiento. El fondo marino existente en Las Amoladeras, proclive en la antigüedad al fuerte oleaje, ha sido el causante de que muchos barcos encallaran y naufragaran en sus aguas, por lo que la existencia de distintos pecios es una realidad. Hubo que esperar hasta las décadas de 1970 y 1980 para que J. Mas, cartagenero pionero de la arqueología subacuática, realizase una serie de prospecciones en Las Amoladeras. Apoyado por buceadores aficionados, su equipo recuperó distintos materiales arqueológicos, aunque lo hicieron de forma discontinua.

1 Queremos agradecer a L. Á. Torres Sobrino, por permitirnos acceder a estos fondos, depositados en el ARQUA. También nuestro agradecimiento para A. Arévalo (Univ. de Cádiz), J. A. Antolinos (Univ. de Murcia), C. Stannard (Univ. of Leicester), I. Montero (CsIC), C. Carreras (Univ. Autònoma de Barcelona) y los dos evaluadores anónimos, cuyos comentarios a una versión previa de este artículo han permitido mejorar su versión final.

\section{1. ¿Pecio, embarcadero, fondeadero...?}

Historiográficamente ha existido un productivo debate sobre la naturaleza de este yacimiento subacuático. Mas (1985: 155, 162 y 164) fue el primero que afirmó que el yacimiento de Las Amoladeras correspondía a un embarque de manufacturas de plomo, para acabar concluyendo que, a raíz de la presencia de los plomos monetiformes, se trataba en realidad de un pecio republicano. Posteriormente, Mińano (2006: 14) no dudó en recalcar los problemas que presenta la documentación existente, planteando la posibilidad de que hubiese más de un pecio y la necesidad de emprender nuevas labores de documentación que ayudasen a realizar una valoración más aproximada del yacimiento. En fechas más recientes, Alonso (2009: 39) comenta que, en la playa de Las Amoladeras, se recuperaron distintos materiales que formaban sin lugar a duda parte del cargamento de una embarcación, cargada con manufacturas de plomo. A su vez, Vargas (2013: 162) recoge Las Amoladeras como un barco de los ss. II-I a. C., remarcando la necesidad de realizar un estudio sistemático de las diferentes campañas arqueológicas que han tenido lugar, incluido el estudio de los materiales. El objetivo: "poder precisar el momento exacto de funcionamiento del barco" (Vargas, 2013: 170). Finalmente, hay que citar a Cerezo (2015: 193, n. 27), quien también se decanta por interpretar Las Amoladeras como un pecio y afirma que se trata de un buen ejemplo de uso de lingotes reutilizados a bordo para fabricar proyectiles.

Si bien parece haber un cierto consenso en que es necesario estudiar la documentación y los materiales de Las Amoladeras de forma exhaustiva, tarea a la que esperamos que este trabajo contribuya, también parece haberlo a la hora de definir el yacimiento como un pecio. Teniendo presentes los datos existentes y la homogeneidad y especificidad del conjunto de materiales metálicos recuperados, pensamos que esta hipótesis es hoy la más plausible ${ }^{2}$.

2 Tanto la literatura como el material divulgativo disponible hacen hincapié en que se trata de un pecio. Así figura también en el programa Domus/Ceres del Ministerio de Cultura y Deporte, en la Carta Arqueológica Subacuática de Murcia y en el Proyecto SeaQuest del cepoat. 


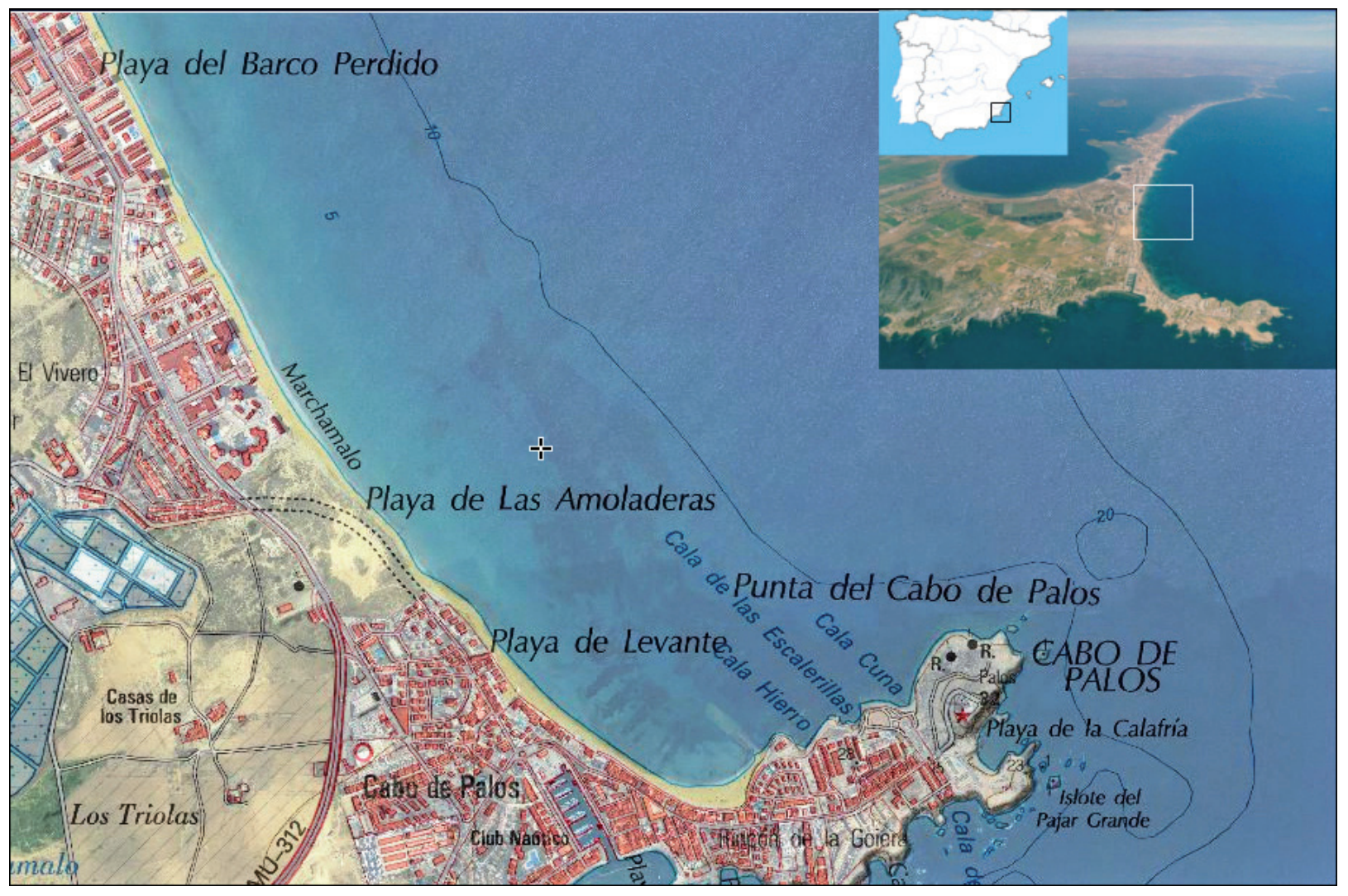

FIG. 1. Situación de la playa de Las Amoladeras, en Cabo de Palos-La Manga del Mar Menor (mapa base del visor SigPac).

\subsection{Los materiales, una breve revisión historiográfica}

Los materiales del pecio de Las Amoladeras se conocen gracias a unas vagas descripciones ${ }^{3}$. La primera de ellas recoge que, en dicho yacimiento, se recuperaron tuberías (o fístulas) de diferentes dimensiones, codos, ensamblajes, figuras y objetos decorativos, glandes, pesas, lañas, plomos para pescar y demás objetos secundarios. Entre estos últimos, se incluyen 4 plomos monetiformes (Mas, 1979: 120; Miñano, 2006: 9). Posteriormente, Mas (1985:

3 Hay que manifestar que, en algunos trabajos, así como en el programa Domus/Ceres, se cita un TFM realizado en principio por Sánchez Angosto, A.: El inventario de materiales del yacimiento subacuático de Las Amoladeras, en 2013 en la Univ. de Murcia. Tras ponernos en contacto con S. F. Ramallo y el propio ARQUA, se nos confirmó que el TFM no se leyó y que tampoco se depositó copia alguna del supuesto manuscrito, por lo que no lo hemos incluido en este estudio.
162), además de reproducir de forma casi íntegra el anterior sumario, añade la exhumación de ánforas y otros materiales: “... Los grandes fragmentos de ánforas revueltos con el expresado cargamento metálico corresponden a la Forma Dressel 1, Lamboglia A [en realidad 2] y entre el material diverso hallado, tégulas, molinos ${ }^{4}$, etcétera, apareció un colgante fálico de oro...”. Además, el investigador sugirió que los plomos monetiformes eran téseras ${ }^{5}$ con escritura ibérica y que estaban relacionados

4 Sobre las ruedas de molino desconocemos su origen exacto, si de la playa o del fondo marino y, por lo tanto, del cargamento original (Miñano, 2006: 13).

5 En este trabajo haremos referencia a 'piezas' o 'plomos monetiformes' y no a téseras con el fin de evitar la discusión sobre la naturaleza de su función. El término tésera se aplica también en numismática clásica, dado que existen otras piezas monetarias (Rostovtzeff, 1903), también emitidas en oricalco (Martínez Chico, 2019). 
con Sierra Morrena, cosa que podría determinar el origen de toda la 'mercancía metalúrgica' (sic). Dos años después, Domergue (1987: 356-357) afirmó que de la playa de Las Amoladeras también se recuperaron algunos fragmentos de pirita y galena, pobres en plata.

Hace algo más de una década, Miñano (2006) realizó una revisión crítica de estos materiales procedentes de Las Amoladeras, algunos depositados actualmente en el Museo Nacional de Arqueología Subacuática -en adelante ARQUA- y recogidos en las notas de Mas (1979: 120 y 1985: 162). Sin embargo, nos enfrentamos a una información imprecisa y bastante escueta, cosa que dificulta la reconstrucción arqueológica del pecio, su cargamento y ulterior interpretación. La autora concluyó que, a juzgar por los materiales recuperados en Las Amoladeras, parecen estar representados dos momentos distintos. De acuerdo con esto, los materiales ferrosos, así como algunas anclas, tuercas, tornillos y una bala, fueron descartados al considerarse elementos contemporáneos, producto de arrastres o alteraciones posdeposicionales. Por tanto, el pecio romano objeto de este estudio, y del que supuestamente también se recuperaron restos de madera, estaría formado por un cargamento con manufacturas fundamentalmente de plomo (Miñano, 2006: 9 y 13).

Según Miñano (2006: 11-14), en el libro de registro del ARQUA se citan diversos objetos elaborados en distintos metales y entre los cuales podemos destacar los fragmentos de una vasija, una plancha $-n$. ${ }^{\text {os }}$

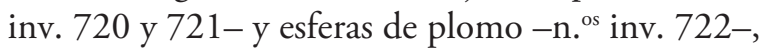
otra plancha del mismo metal cuya forma casual recuerda a un delfín $-n .^{\circ}$ inv. 727-, un aro $-n .^{\circ}$ inv. 729- y un pasador de plomo -n..$^{\circ}$ inv. 731-, y que pudieron formar parte del mismo pecio. El registro lo completan fragmentos de tuberías, lañas y aros de plomo que fueron reinventariados a finales de la década de los $80-n$. os inv. 50.281-50.284-, y la tubería -n..$^{\circ}$ inv. 50.334- que ya citó en su día Mas García.

En cuanto a las pesas -n. ${ }^{\text {os }}$ inv. 714-719, 4.434/1 y 15.624/1.1-1.5-, las 6 primeras son pesas troncopiramidales y el resto pesas de red, con forma de plancha enrollada. Otros materiales del pecio no corrieron la misma suerte, como es el caso de las piezas de ensamblaje, que no están actualmente en el museo. Algo parecido ocurre con los 4 plomos monetiformes descritos por Mas (1985: 162), pues en el museo solo hay $3-n{ }^{\text {os }}$ inv. 50.336-50.338-y el cuarto está desaparecido. De los 160 glandes que citó Mas (1979: 120), en realidad en el museo hay depositados $170-$ n..$^{\text {inv. }}$ 50.318-: 122 en el almacén y 48 en la exposición permanente.

También del pecio de Las Amoladeras procedería un lingote de plomo con el resello $M M I N-\mathrm{n} .^{\circ}$ inv. 88.122- y un amuleto fálico de oro $-n .^{\circ}$ inv. $50.275-$, sin duda la pieza más destacada y que muy posiblemente perteneció a un miembro de la tripulación.

\section{Los plomos monetiformes}

Como hemos dicho con anterioridad, fue Mas (1985: 162 y 164, lám. III) quien documentó el hallazgo de 4 plomos monetiformes en las aguas de Las Amoladeras -n. ${ }^{\text {os }}$ inv. 50.336-50.338-. Estas piezas nunca han sido estudiadas en detalle. Tras consultar la bibliografía en la que se discuten estos plomos, comprobamos que únicamente existen referencias indirectas, siendo buenos ejemplos el trabajo monográfico de plomos realizado por Casariego et al. (1987: 89), así como el de Rodríguez Gavilá (2017: 81). Los primeros autores no pudieron incorporar a tiempo dichos ejemplares en su catálogo, por lo que remitieron a la publicación de Mas García, proponiendo como sugerencia, a partir de la figura del reverso y dada su similitud con la icónica bellota onubense, que uno de los plomos aludía a las amonedaciones de Ostur. Sin embargo, Rodríguez Gavilá (2017: 81) señaló recientemente que los plomos de Las Amoladeras pertenecían en realidad a Pollentia, mientras que otros autores prefieren mantener la tradicional asociación de estas piezas con Ostur (Arévalo y Moreno, 2017: 178-179).

En realidad, la adscripción geográfica de estos plomos ha sido un problema difícil de solucionar, pese a los intentos de Mas (1985: 162) de situarlos en Sierra Morena. Si bien es cierto que la inmensa 
mayoría de los plomos monetiformes conocidos proceden y fueron emitidos en la Baetica, hoy sabemos que la difusión y el uso de plomos monetiformes no fueron exclusivos de una única zona ${ }^{6}$. Son buenos ejemplos, entre otros, las series denominadas ítalo-béticas

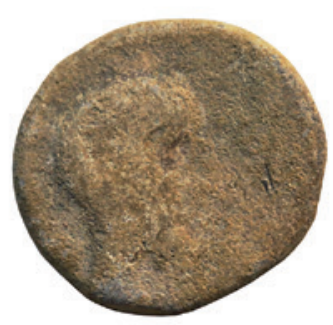
1 (Stannard et al., 2017 y 2019), que gozaron de una amplia difusión documentándose en territorios habitados por grupos con lenguas y culturas bien diferenciadas $^{7}$, o los plomos monetiformes con el topónimo ibérico kaitur = gaidur, localizados en Susaña, Mazarrón (Guillén, 1999; García-Bellido, 2001).

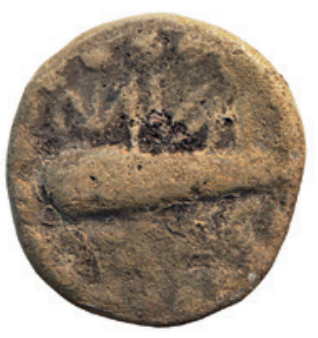

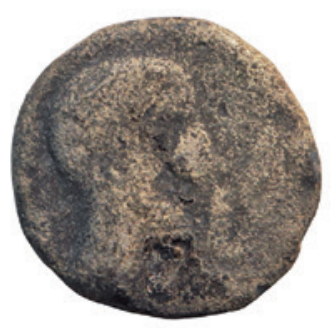

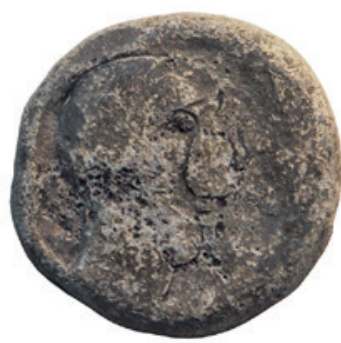

2

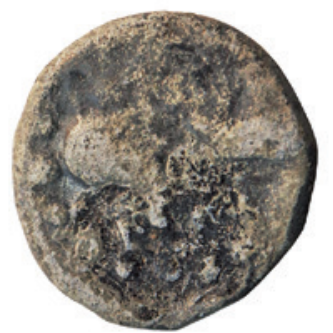

3

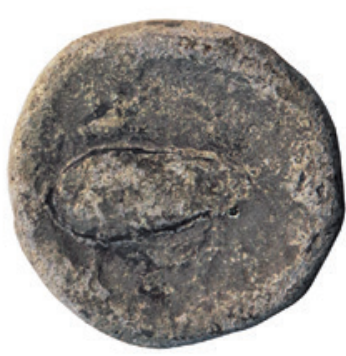

$5 \mathrm{~cm}$

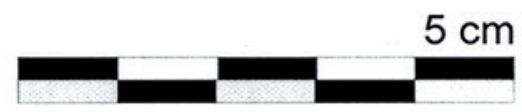

FIG. 2. Plomos monetiformes de Las Amoladeras (cortesía del ARQUA).

\begin{tabular}{|c|c|c|c|c|c|c|}
\hline N. ${ }^{\circ}$ & N. ${ }^{\circ}$ INV. & ANVERSO & Reverso & $\begin{array}{l}\text { Módulo } \\
\text { (мM) }\end{array}$ & $\begin{array}{l}\text { Peso } \\
(\mathrm{G})\end{array}$ & EJE \\
\hline 1 & 50.338 & $\begin{array}{l}\text { busto de Hércules (?) } \\
\text { a dcha. }\end{array}$ & $\begin{array}{l}\text { maza dispuesta horizontalmente, encima } \\
\text { leyenda latina; orla punteada }\end{array}$ & 33 & 34,8 & 3 \\
\hline 2 & 50.336 & $\begin{array}{l}\text { busto de Hércules (?) } \\
\text { a dcha.; delante letra L (?) }\end{array}$ & $\begin{array}{l}\text { maza dispuesta horizontalmente, abajo } \\
\text { restos de leyenda (?); orla punteada }\end{array}$ & 33 & 37,6 & 2 \\
\hline 3 & 50.337 & $\begin{array}{c}\text { busto de Hércules (?) } \\
\text { a dcha. }\end{array}$ & $\begin{array}{l}\text { maza algo más gruesa, dispuesta } \\
\text { horizontalmente }\end{array}$ & 35 & 68,1 & 12 \\
\hline
\end{tabular}

FIG. 3. Catálogo de los plomos monetiformes de Las Amoladeras.

A nivel general y pese a ser un tema difícil de solucionar, los plomos monetiformes se han considerado en el pasado como una especie de moneda local, restringida entre las empresas y sus distritos mineros, a veces situados en diferentes sedes, pero especializadas en los procesos de extracción, fundición y exportación del mineral (Casariego et al., 1987: 100;

6 Así lo demuestra el ejemplar hallado en Cerro Lucena (Enguera, Valencia), con escritura ibérica nororiental y emitido seguramente en el entorno de Carthago Nova a finales del s. II o principios del i a. C. (Stannard et al., 2017).

7 Un estado de la cuestión sobre las lenguas y epigrafías paleohispánicas puede encontrarse en Sinner y Velaza (2018 y 2019).
García-Bellido, 2001: 335). Otros plomos algo más tardíos, como los emitidos por $N$. Caleci (Casariego et al., 1987: 34, n. ${ }^{\circ}$ 6bis; Stannard et al., 2017: 96, figs. 69-71), se han relacionado con un negotiator itálico, cuyas piezas, con representaciones de Vulcano, Hércules y Júpiter en anversos, pudieron haberse suministrado a sus trabajadores (García-Bellido, 1986: 26, figs. 23-24; Rodríguez Gavilá, 2017: 83-84) ${ }^{8}$.

8 De forma similar podrían interpretarse otras piezas cartageneras, aunque en bronce, con martillo y aspergillum (?) y otras que parecen aludir a un negotiator de origen itálico, llamado Marcus Acilius Maximus, cf. Martínez Chico, D. y González García, A. (en prensa): "Tessera con epígrafe $M \cdot A C I$ MAX y su posible identificación”, Athenaeum, 108 (2). 
En nuestra opinión, la exclusiva vinculación de estos plomos con la actividad minera debe relativizarse. Los 'grandes plomos', al igual que los de $N$. Caleci, forman parte de las series ítalo-béticas, las cuales incluyen entre sus tipos a un furnacator, personaje que alimenta hipocaustos en los baños públicos y que se ha asociado erróneamente con la minería debido a la pala que carga sobre su hombro (Stannard et al., 2019: 127-128). La asociación iconográfica del furnacator con los estrígilos apuntaría a un contexto de uso muy distinto. Del mismo modo, la lectura de algunas de estas piezas con leyenda $P \cdot S$ como $P$ (ublica) S(ocietas) es igualmente controvertida (García-Bellido, 1986: 29-30). De hecho, actualmente prevalece la visión de que los publicani romanos no poseían compañías mineras, ya que es posible que las minas fueran declaradas ager publicus y explotadas siguiendo un régimen de ocupatio (Rico, 2010: 407-409; Díaz Ariño y Antolinos, 2013: 551-553). Lo que sí que parece estar fuera de duda es la existencia de una importante circulación local de este tipo de plomos en pleno cinturón minero del SE hispano -Cástulo, Gádor, Mazarrón y Cartagena-La Unión-.

\subsection{Los plomos de Las Amoladeras}

Otro de los focos donde se documentan los plomos monetiformes es el estudiado y documentado por Trilla y Calero (2008) desde Pollentia. Dichos autores documentaron una serie de plomos que a día de hoy sabemos que proceden de distintos puntos de la isla de Mallorca. Un buen ejemplo es la pieza procedente de la María de la Salut (Fig. 4, n. ${ }^{\circ}$ $4)^{9}$, que hemos caracterizado isotópicamente en este trabajo en lugar de los ejemplares del ARQuA (Figs. 2 y 3$)^{10}$. Fuera de Mallorca, también se han documentado plomos procedentes del poblado talayótico de Sa Talaia de Biniancollet, al s de Sant Lluís,

9 Agradecemos a J. Orell Jaquotot y a J. Boada Salom, miembros de la SCEN, que nos hayan permitido analizar uno de sus plomos para el presente estudio.

${ }_{10}$ Debido a la naturaleza destructiva de los análisis no se nos permitió analizar dichos ejemplares.
Menorca (Nicolás y Obrador, 2017: 165). El resto de los ejemplares conocidos proceden de colecciones particulares de la isla de Mallorca, pero carecen de contexto arqueológico (Sabaté, 2017: 199-200).

Los plomos monetiformes de Las Amoladeras pertenecen al denominado de tipo maza (Trilla y Calero, 2008: 72-80). No obstante, es importante mencionar la existencia de un subtipo, pues hay ejemplares con leyenda CPADIR, posiblemente aludiendo a Gadir, lo que ha llevado a plantear que, en Pollentia, parte de los colonos llegados tras la conquista de la isla procedían de Gadir (Trilla y Calero, 2008: 77). Sin duda, la maza hace referencia a Hércules, por lo que el busto masculino del anverso, aunque tosco, seguramente corresponda al del hijo de Zeus y Alcmena. La maza es un elemento iconográfico que gozó de gran popularidad en el mundo grecorromano, como así lo indica su presencia en el reverso de una conocida emisión de denarios de Octaviano, acuñada por Lucius Cornelius Balbus en el

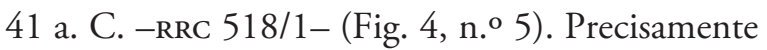
este denario es el que se ha señalado como el posible prototipo de los plomos con maza (Trilla y Calero, 2008: 77-79).

Por otra parte, se ha realizado una diferenciación acorde al estilo de las piezas. En realidad, los plomos, aunque constituyen una misma serie, forman parte de distintas emisiones. Las dos primeras (Fig. 3, n. ${ }^{\text {os }} 1-2$ ) concuerdan con otras ya conocidas (Trilla y Calero, 2008: 73-74, n. ${ }^{\text {s }} 1-2$ ). El fuerte desgaste de la gran mayoría de plomos y, en concreto, en la zona escrituraria, localizada en los campos superior e inferior de la maza, hace que la lectura casi siempre sea problemática. No obstante, algunos ejemplares conocidos actualmente, procedentes de la isla de Mallorca, poseen una mejor conservación (Fig. 4, n. ${ }^{\text {os }} 1-4$ ). Esto ha permitido llevar a cabo una lectura más precisa que la que era posible a partir de los ejemplares de Las Amoladeras. La primera lectura propuesta fue la que realizaron Trilla y Calero (2008: 72), quienes manifestaron que el signario era de tipo ibérico del s, leyendo en el campo superior de la maza MVM o TM VM (SKaS o TNKaS) y, en el inferior $T \cdot P \underline{A V C}$ o $\underline{A V K}(\underline{A K})$. 
Posteriormente, esta lectura fue revisada. Sabaté (2017: 200) cuestiona la lectura del epígrafe superior, sugiriendo que si “... juzgamos la leyenda como latina, de izquierda a derecha tendríamos $(+)+N V M \quad-$ donde la forma invertida de $<N>$ se debería a un error en la fabricación del cuño por no haberse tenido en cuenta el efecto espejo- $y$, de derecha a izquierda, obteniendo como resultado la lectura de $M V N+(+) .$. ", por lo que estaríamos ante una lectura levógira con la típica abreviatura de municipium, frecuente en leyendas monetales. En la lectura del epígrafe inferior sí que hay consenso

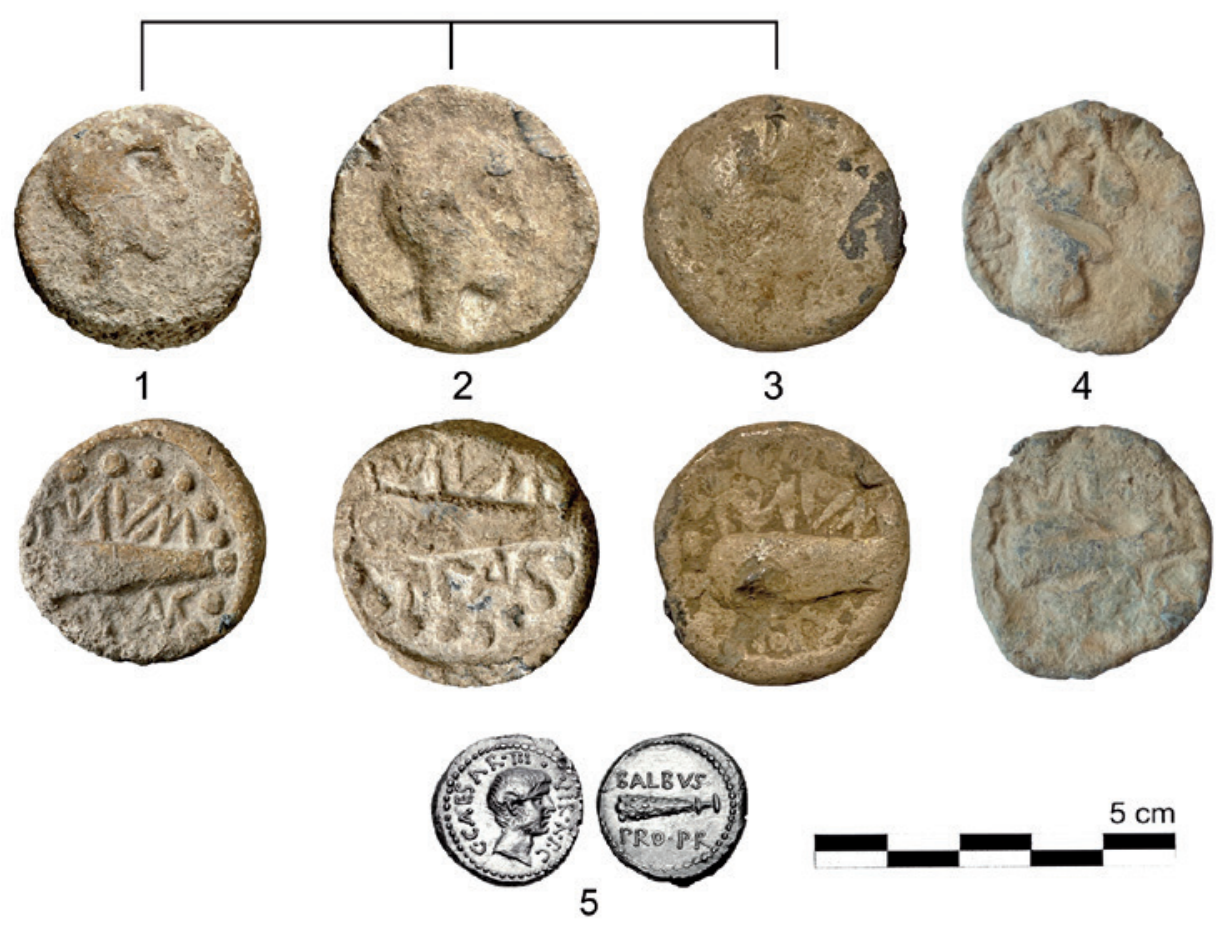

Fig. 4. Ejemplares de plomos con mejor conservación y enlaces de cuños documentados (1-4) y moneda (5) con tipos relativamente similares: 1) $40,57 \mathrm{~g}$ y $31 \mathrm{~mm}$;) $39,77 \mathrm{~g}$ y $36 \mathrm{~mm}$; 3) $44 \mathrm{~g}$ y $35 \mathrm{~mm}$; 4) $27,44 \mathrm{~g}$ y $33 \mathrm{~mm}$; 5) denario de Octaviano acuñado en $41 \mathrm{a}$. C. (RRC 518/1), 3,92 g y $18 \mathrm{~mm}$ con maza de Hércules y alusión al magistrado monetal $\mathrm{L}$. Cornelius Balbus, propretor oriundo de Gadir (imágenes 1 y 2 según Trilla y Calero, 2008: 73-74; n. ${ }^{\circ}$ 1-2; 3-4 de cols. privadas de Mallorca; 5 según Classical Numismatic Group, Tritón XVI [08/01/2013], lote 973).

acerca de su latinidad

(Trilla y Calero, 2008: 72; Sabaté, 2017: 200-201; Nicolás y Obrador, 2017: 166-167), obteniendo la siguiente lectura como definitiva: $+N V M$ / [T.PA VK].

El estudio paleográfico ha determinado que el uso de una $<$ P $>$ con panza abierta podría indicar una cronología republicana (Sabaté, 2017: 200), dato que concuerda con la cronología que proponemos para Las Amoladeras - $c f$. infra-. Hay que destacar que esta emisión de plomos monetiformes es la más antigua entre las conocidas en Pollentia. Tanto el primer como el segundo plomo monetiforme de Las Amoladeras (Figs. 2 y 3, n. ${ }^{\text {os }} 1-2$ ) se ajustan a una misma media metrológica, pero en el reverso del segundo no se visualiza leyenda alguna, relegada a meros trazos o puntos amorfos. No obstante, en

su anverso sí que podría verse una L frente al busto, aunque esto tampoco es seguro. El anverso asociado a estos primeros plomos es el que más se asemeja al de las monedas de Cástulo. En muchas de las emisiones castulenses con epigrafía ibérica, frente a las cabezas masculinas, encontramos distintos símbolos -ACIP n. ${ }^{\text {s }} 2116-2117$ y 2133-2159-, además de la letra latina L -e. g. ACIP n. ${ }^{\text {os }} 2156-2159-$. Su datación concordaría incluso con una cronología tardía del s. I a. C. Finalmente, el tercer plomo monetiforme de Las Amoladeras, también sin leyenda, posee un arte todavía más tosco (Figs. 2 y 3, n. ${ }^{\circ} 3$ ), pero, en cualquier caso, muy similar a los estudiados por Trilla y Calero (2008: 74-75, n. ${ }^{\text {os }} 3-5$ ), con pesos cercanos a los 68,1 g que presenta el ejemplar de Las Amoladeras. 


\section{El lingote de plomo}

El lingote en cuestión fue estudiado por Díaz Ariño (2006: 291), aunque en ese caso no se contextualizó como procedente del pecio de Las Amoladeras. El autor únicamente menciona que es posible que proceda de las inmediaciones de Cartagena. Actualmente, sabemos que el lingote con resello MMIN procede de Las Amoladeras gracias a la revisión emprendida en los fondos museográficos (Miñano, 2006: 12) ${ }^{11}$, y así consta en el inventario del ARQua. Existiendo un estudio previo, aquí solo expondremos los aspectos de dicho trabajo que resulten relevantes.

Tipológicamente hablando estamos ante un lingote de planta rectangular y sección trapezoidal (Fig. 5). Sus dimensiones son $25 \mathrm{~cm}$ de longitud por $8,5 \mathrm{~cm}$ de anchura y $8,7 \mathrm{~cm}$ de altura y presenta muchas similitudes con lingotes clasificados por Domergue (1990: 253) como del Tipo I (Domergue y Rico, 2018). Cronológicamente, estos lingotes se pueden fechar grosso modo en la segunda mitad del s. I a. C. o a comienzos de la centuria siguiente. Formalmente, lo que hace este lingote especial es el hecho de que mide y pesa aproximadamente la mitad que los lingotes del Tipo I de Domergue. Díaz Ariño (2006: 291) plantea la hipótesis de que la pieza fue concebida originalmente con estas dimensiones, aunque, tras una detallada inspección, pensamos que podría tratarse de un ejemplar cortado, lo que explicaría que pese la mitad de lo esperado ${ }^{12}$. Sea como fuere, la presencia de un único lingote indica que posiblemente se tratase de uno de los enseres de la tripulación. La presencia de lingotes en los barcos antiguos es común ya que el metal se utiliza en reparaciones, así como en la fabricación de objetos para la tripulación, incluidas las actividades

11 Dicha revisión de los materiales tuvo lugar con posterioridad a la publicación de Díaz Ariño.

12 En la Fig. 5 se pueden apreciar evidencias de manipulación como, por ejemplo, una hendidura previa en el lomo o el hecho de que los laterales cortos del lingote presentan acabados muy distintos, quizás debido a que uno de ellos fue seccionado. Por otro lado, es cierto que, si se tratara de un lingote cortado, debería esperarse que tuviese alguna cartela en el lomo. pesqueras entre otras cotidianas de la nave (Vargas, 2013; Cerezo, 2015).

El segundo aspecto que nos interesa resaltar es la existencia en la parte central superior del dorso del lingote de un resello $M M I N$, realizado en frío. Si bien la presencia de resellos de este tipo es común en lingotes imperiales de plomo (Colls et al., 1986: 57, 63-70; Domergue 1994: 62-63; Domergue y Rico, 2018), son menos frecuentes durante el periodo republicano, cuyas contramarcas solo se atestiguan en cuatro ocasiones (Díaz Ariño, 2006: 292, n. 5). Normalmente, los resellos en frío no aparecen en solitario, sino acompañando a la/s cartela/s principales -normalmente entre una y tresque aparecen en positivo en los lingotes. Además, llama la atención la posición de esta marca, en un lugar donde se esperaría encontrar la cartela principal, ya que los resellos habitualmente se encuentran en los laterales o en las caras cortas de los lingotes. Los resellos suelen darnos una información distinta a la vez que complementaria a la que nos ofrecen las cartelas principales. Estas últimas normalmente hacen referencia al beneficiario de la explotación, mientras que los resellos, aunque su interpretación es algo más controvertida, parece que identifican a los comerciantes, transportistas y otros individuos implicados en la comercialización del metal (Domergue, 1998; Rico, 2011).

En resumen, el resello podría interpretarse bien como el beneficiario de la explotación minera o bien como el personaje que lo comercializa. En opinión de Díaz Ariño (2006: 292), la primera opción es la más factible, teniendo presentes las características de la pieza y su cronología. Posteriormente, el autor argumenta de forma detallada la relación existente entre este gentilicio latino, frecuente en Italia, pero poco común en el solar hispano, y la minería del plomo en Hispania, argumentos que no repetiremos aquí, pero con los que coincidimos (Díaz Ariño, 2006: 293-294). El investigador concluye su estudio planteando la posibilidad de que el Minicius de nuestro lingote podría corresponderse con el $M i$ nicius Pica mencionado por Varrón y al que se podría situar en Cartagena gracias a la aparición de un lingote en el que se puede leer [---]Picae (Domergue 

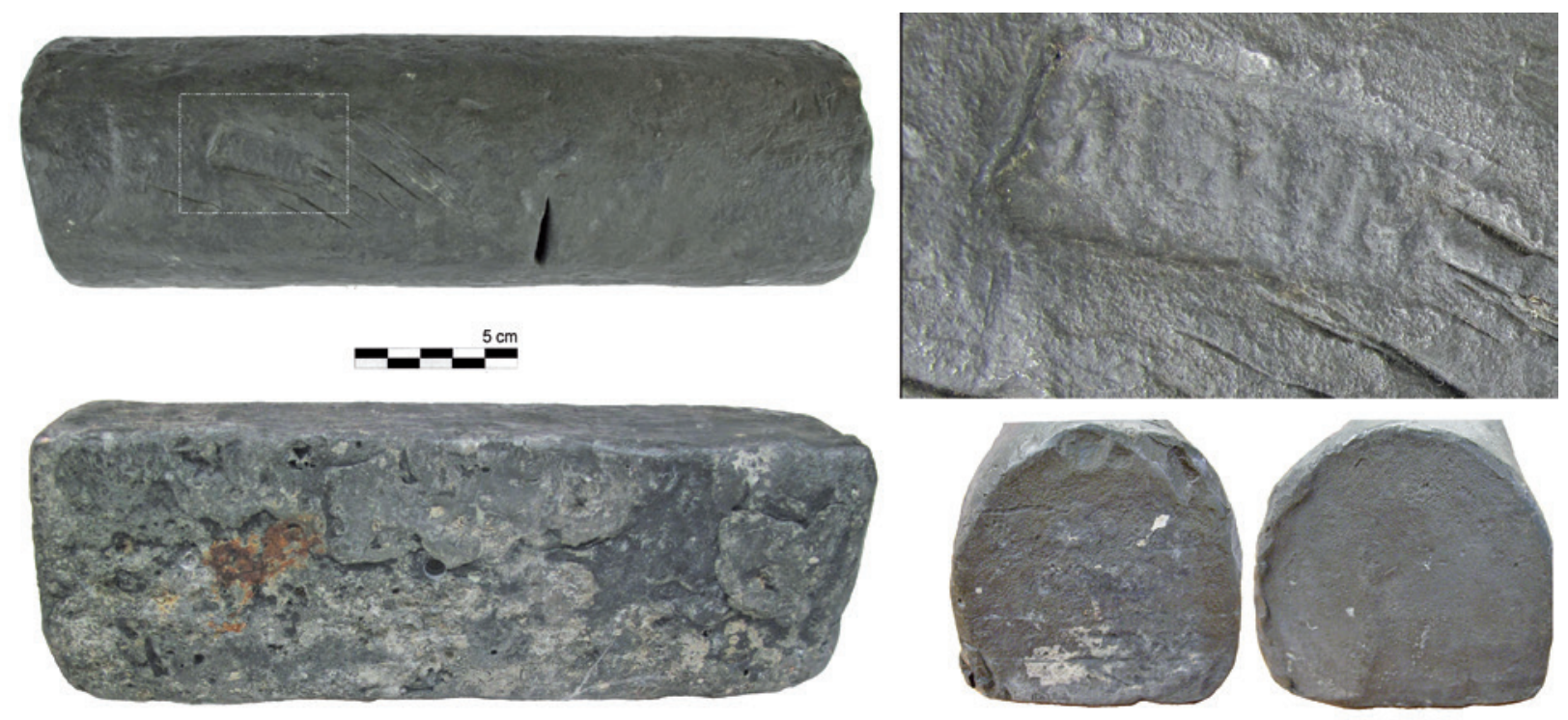

FIG. 5. Lingote resellado con MMIN (Marcus Minucius) (imágenes cortesía del ARQUA).

y Mas García, 1983: 907-909; AE, 185-186), o ser un descendiente suyo (Díaz Ariño, 2006: 294). Como veremos a continuación, la caracterización isotópica llevada a cabo sitúa la explotación de los Minucii, o al menos el metal del lingote, en las minas de Cartagena-Mazarrón.

\section{Comentarios sobre otros materiales destacados}

\subsection{Objetos de la tripulación}

De entre los enseres de la tripulación de Las Amoladeras nos llegan objetos de gran interés, los cuales nos aproximan a la vida y a las creencias de los tripulantes del navío. La pieza más excepcional, no solo por su valor material sino por su carga ideológica y simbólica, es un colgante apotropaico de oro de pequeńas dimensiones -13 × $8 \mathrm{~mm}-$. En un extremo presenta una figuración fálica, con un par de testículos, y en el otro una higa poco trabajada (Fig. 6). En la zona superior se encuentra la argolla para su suspensión en colgante. Este amuleto fálico es similar al hallado en Bilbilis (Sáenz y Lasuén, 2004), aunque el bilbilitano es más esquemático ya que se confeccionó a partir de una lámina metálica y no mediante vástago cilíndrico, como es el caso del nuestro. Tanto el amuleto de Bilbilis como el de Las Amoladeras se ajustan al Grupo vi de amuletos fálicos exentos A o Colgantes 3.2, con higa/falo (Hoyo y Vázquez Hoys, 1996: 454-455). El hecho de que se haya confeccionado en oro y no en bronce o plomo puede responder, según Plinio (Nat. His., 23.4.25), a un intento de potenciar el efecto filactérico, pero también nos informa del estatus social de su propietario, quien, como mínimo, disponía del suficiente poder adquisitivo como para procurarse un objeto de estas características.

Los fascina áureos son muy escasos en el solar hispano. Solamente se conocen el encontrado en Los Bañales (Uncastillo, Zaragoza), que, por tipología y contexto -TSH altoimperial- se puede fechar en el s. I o comienzos del iI d. C., y, muy próximo en el tiempo, el ejemplar documentado en Iruña-Veleia (Andreu y Urrizburu, 2019: 323). En Segobriga también se ha documentado un amuleto fálico, aunque se empleó coral para su realización (Sáenz y Lasuén, 2004: 225).

La cronología de los fascina está aún por precisar, pues la mayoría carece de contextos arqueológicos que permitan proponer una datación aproximada. El pecio de Las Amoladeras contribuye en parte 


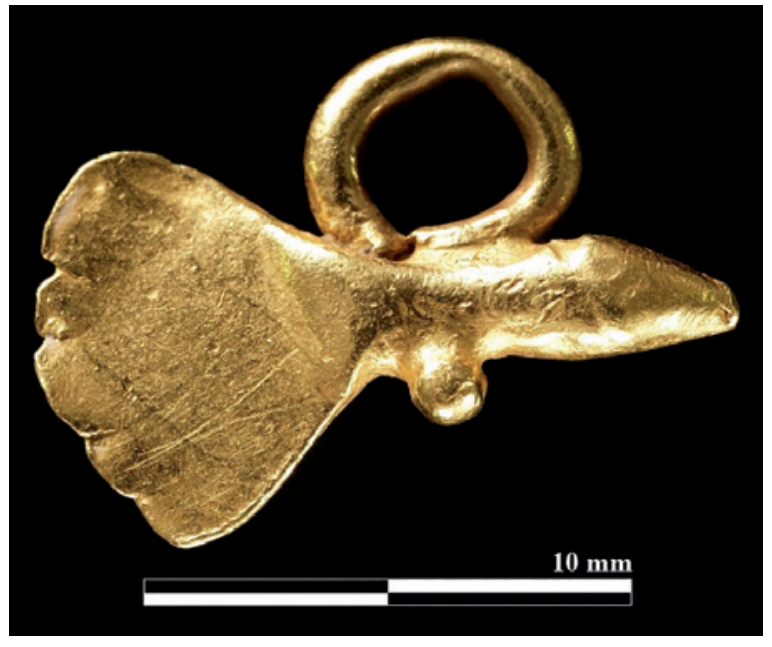

FIG. 6. Amuleto fálico de oro con higalfalo (imagen cortesía del ARQUA).

a solventar este problema ya que nos proporciona al menos el terminus ante quem de fabricación. Los ejemplares más modestos se confeccionaron en bronce y plomo, como el reciente falo alado encontrado por un buzo aficionado en el so de la Isla de Adentro, en el Puerto de Mazarrón. A la espera de su publicación definitiva, este, sin embargo, parece mucho más tardío que el de oro de Las Amoladeras. En cualquier caso, el mazarronero plúmbeo presenta restos de un baño en oro, y quizás date de finales del s. I o principios del II d. C. ${ }^{13}$.

La presencia de un amuleto con función apotropaica, entre alguno de los tripulantes o pasajeros del navío, casa bien con el tipo de creencias que dan lugar a la tradición romana de emplazar monedas en el hueco de la carlinga de las naves como acto augural para una buena travesía (Blay, 2004; Carlson, 2007). El corpus actual consta de 13 pecios, varios de los cuales coinciden aproximadamente con la cronología de Las Amoladeras (Fig. 7, n. ${ }^{\text {os }} 4-6$ ). El hecho de que, en alguna ocasión, se ha recuperado el mástil in situ sin presencia de monedas, nos indica que esta práctica no fue generalizada.

Otros objetos de interés para conocer las actividades a bordo del navío que naufragó en Las

13 https://cutt.ly/bwGeRva / a través de mazarron.es; acceso 13/09/2019.
Amoladeras son las pesas de plomo utilizadas para la pesca, e imprescindibles para suministrar alimentos a los navegantes durante la travesía. Dichas piezas han sido publicadas individualmente por Vargas (2013: 170), quien ya manifestó la necesidad de estudiar los materiales de Las Amoladeras en su conjunto. Según el autor, las pesas son troncopiramidales en su mayoría y se utilizarían a través de su aprehensión mediante sedal, el cual quedaba atado a las pesas (Vargas, 2013: 171). Este tipo de lastres se documentan en la pesca con caña y/o sedal, realizada desde la propia embarcación (Fig. 8), como bien sugiere su elevada presencia en pecios (Bernal, 2010: 214). Desafortunadamente, para evitar extendernos en demasía, no podemos tratar aquí otros materiales como las láminas o planchas, aros, esferas, pasadores, etc., para los que remitimos al lector a trabajo de Miñano (2006).

\subsection{Cargamento}

De los materiales de plomo que posiblemente conformaban el cargamento del barco, hay que mencionar la tubería con el número de inventario 50.334. El tramo conservado presenta una longitud de $340 \mathrm{~mm}$ y un diámetro máximo de $60 \mathrm{~mm}$. Su peso oscila en torno a los $310 \mathrm{~g}$ y posee una forma longitudinal (Fig. 9). Su sección circular está recorrida por una línea de unión, producida durante el proceso de su fabricación. Las tuberías romanas de plomo se fabricaban doblando una lámina de plomo alrededor de una barra de madera, reemplazándola posteriormente con arena o arcilla. Algunos investigadores han sugerido que esta costura se podía soldar tanto con plomo como utilizando soldaduras que generalmente contenían entre un 5 y un 25\% de estaño (Wyttenbach y Schubiger, 1973: 201202, citando a Gowland, 1901).

El hecho de que la tubería haya sido localizada en un pecio, que además se encuentre fraccionada y que uno de sus extremos esté aplastado parece indicar que se trata de los restos extraídos de una canalización y cuyo destino final era el reciclaje. Sobre estos temas, volveremos más adelante al tratar 
la caracterización isotópica de este objeto. El uso de tuberías de plomo en ciudades hispanas se documenta ya en la segunda mitad del s. II a. C. en

\begin{tabular}{|c|l|l|l|}
\hline N. ${ }^{\circ}$ & \multicolumn{1}{|c|}{ Pecio } & \multicolumn{1}{c|}{ Cronología } & \multicolumn{1}{c|}{ Moneda } \\
\hline 1 & Chrétienne A & 2.a $1 / 2$ del s. II a. C. & 1 púnica de Cosura \\
\hline 2 & Spargi & último $1 / 4$ del s. I a. C. & 1 indeterm. \\
\hline 3 & Cavalière & fines del s. I a. C. & 3 ilegibles \\
\hline 4 & La Madrague de Giens & mediados del s. I a. C. & 1 sextans de Roma \\
\hline 5 & Plane 1 & mediados del s. I a. C. & 1 unidad de Ae de Kese \\
\hline 6 & Titan & mediados del s. I a. C. & 1 as semiuncial romano \\
\hline 7 & Cap del Vol & cambio de Era & 1 unidad de Ae de Bolśkan \\
\hline 8 & Diano Marina & mediados del s. I d. C. & 1 indeterm. \\
\hline 9 & Black-Friars & finales del s. I d. C. & 1 as de Domiciano \\
\hline 10 & Calanque de l'Âne & finales del s. I d. C. & 1 as de Domiciano \\
\hline 11 & Pointe de Luque & s. II d. C. & 2 indeterm. de Adriano \\
\hline 12 & Grado & mediados del s. II d. C. & I Ae ilegible \\
\hline 13 & L'Anse Gerval & s. IV d. C. & 1 indeterm. de Constantino I \\
\hline
\end{tabular}

Fig. 7. Pecios en los que se han documentado monedas en el hueco de la carlinga (Blay, 2004; Carlson, 2007).
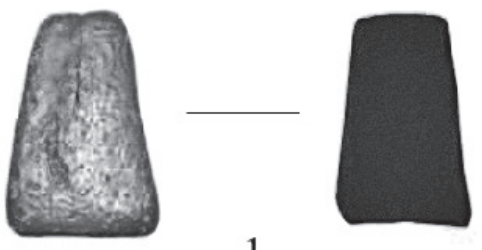

1
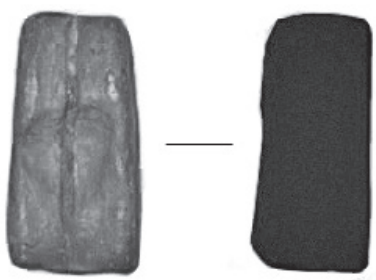

3

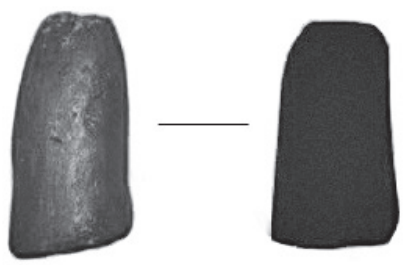

5

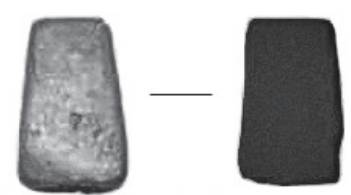

2
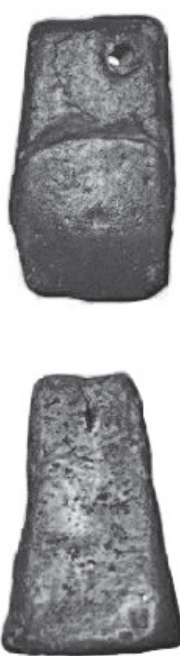

6

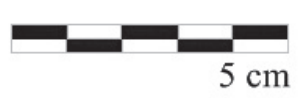

$5 \mathrm{~cm}$
4
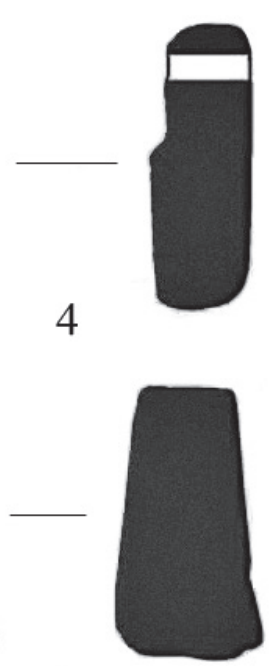

6 las termas de Cabrera de Mar (García Roselló et al., 2000) y Valentia (Marín y Ribera, 2009), y será cada vez más frecuente a medida que avanzamos en el tiempo, teniendo ejemplos de su uso en espacios públicos y domésticos de diversas ciudades hispanas (Guitart, 2007: 2937; Gomes et al., 2016).

Finalmente, según Mas (1979: 120), fueron 160 los glandes recuperados en Las Amoladeras (Fig. 10b). El elevado número de estos objetos pensamos que permite interpretar el conjunto de glandes como parte del cargamento. Desafortunadamente no se pudieron efectuar análisis isotópicos a ninguna de estas piezas, que, si bien normalmente se fabricaban in situ, estudios recientes han documentado en su producción, tanto el uso de metal reciclado como la utilización de mineral extraído de depósitos geológicos (Gomes et al., 2017: 152-153). Otro aspecto que destaca es la relación existente entre la metrología y la cronología de este tipo de materiales. Según estudios recientes (Quesada et al., 2015: 351 y fig. 18; previamente Völling, 1990), parece que el peso de los glandes puede ser un elemento de datación relativa. Si bien el peso de los proyectiles de plomo es variable, los estudios

Fig. 8. Pesas de pesca de Las Amoladeras (Vargas, 2013: 171, fig. 4). 


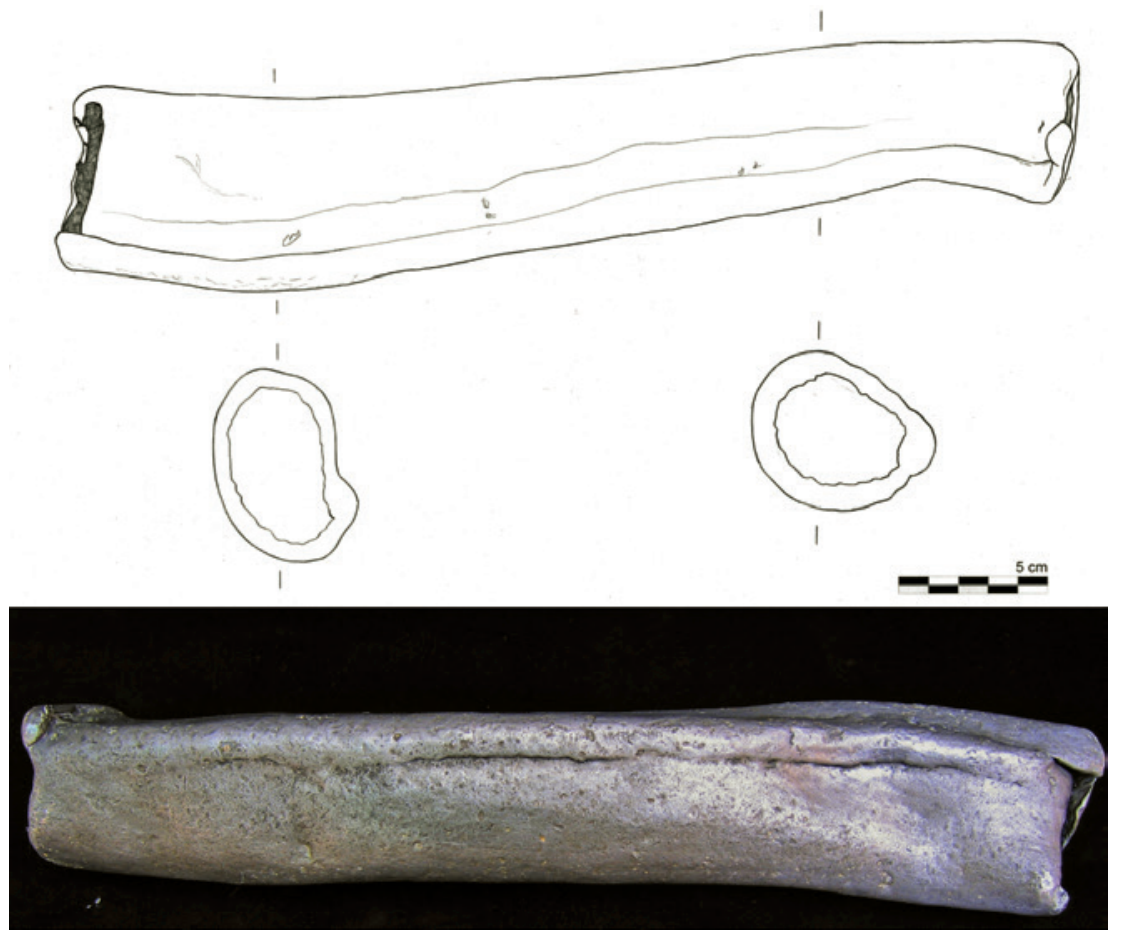

FIG. 9. Tubería de Las Amoladeras (cortesía de M. S. Crespo Ros y ARQUA). subacuático, se han realizado análisis isotópicos de algunos de sus materiales más característicos, concretamente del lingote de $M$. Minucius - n. ${ }^{\circ}$ inv. 88.122 (Fig. 5) - y la tubería de plomo -n. ${ }^{\circ}$ inv. 50.334 (Fig. 9)-. Aunque no se nos permitió analizar ninguno de los glandes o de los plomos monetiformes procedentes de Las Amoladeras, lo que hubiese sido ideal desde un punto de vista metodológico, sí que hemos analizado un plomo monetiforme de la misma serie procedente de una colección privada (Fig. 4, n. ${ }^{\circ}$ ). Si bien no podemos extrapolar los resultados de este análisis a las piezas de Las Amoladeras, el hecho de que la circulación de estos plomos sea de carácter local y documentada exclusivamente en las Islas Baleares, unido a la presencia de cuatro de estas piezas en Las Amoladeras, establece una conexión entre el yacimiento y las islas. Obtener datos sobre el origen del metal y la tecnología de fabricación de estos plomos resulta de interés en un estudio como el que aquí nos ocupa. Además, si en el futuro se llevan a cabo análisis de los plomos de Las Amoladeras, ya existirán resultados con los que comparar.

\subsection{Metodología analitica}

Para llevar a cabo los análisis isotópicos se han necesitado muestras de $0,4 \mathrm{~g}$, que se consiguieron mediante la utilización de un taladro y brocas desechables. En primer lugar, se pulió la superficie de los materiales a muestrear con el fin de eliminar posibles contaminantes. A continuación se procedió a extraer una pequeña cantidad de material en forma de virutas del interior de la pieza. Los análisis se han realizado en un colector múltiple ICP-MS 
(MC-ICP-MS) para realizar mediciones de isótopos de mayor precisión. Estas herramientas están equipadas con varios detectores que miden simultáneamente los diferentes isótopos de interés. El tratamiento químico preliminar de las muestras es de considerable importancia para evitar una posible contaminación. El plomo está muy extendido en el medio ambiente, incluso en el aire, aunque hoy menos que en el pasado reciente. En principio, si la muestra está compuesta solo de plomo, o es lo suficientemente grande, el problema de la contaminación es residual, pero si la muestra es muy pequeña -trazas-, se debe evitar incluso el contacto más mínimo con posibles contaminantes.

Los trabajos se realizaron en una sala limpia de Clase 100, donde se usó FEP -Fluoro EthylenePropylene- ultralimpio en todos los materiales de contención utilizados durante el tratamiento químico. Para optimizar la medición de las relaciones isotópicas con este método, es aconsejable extraer

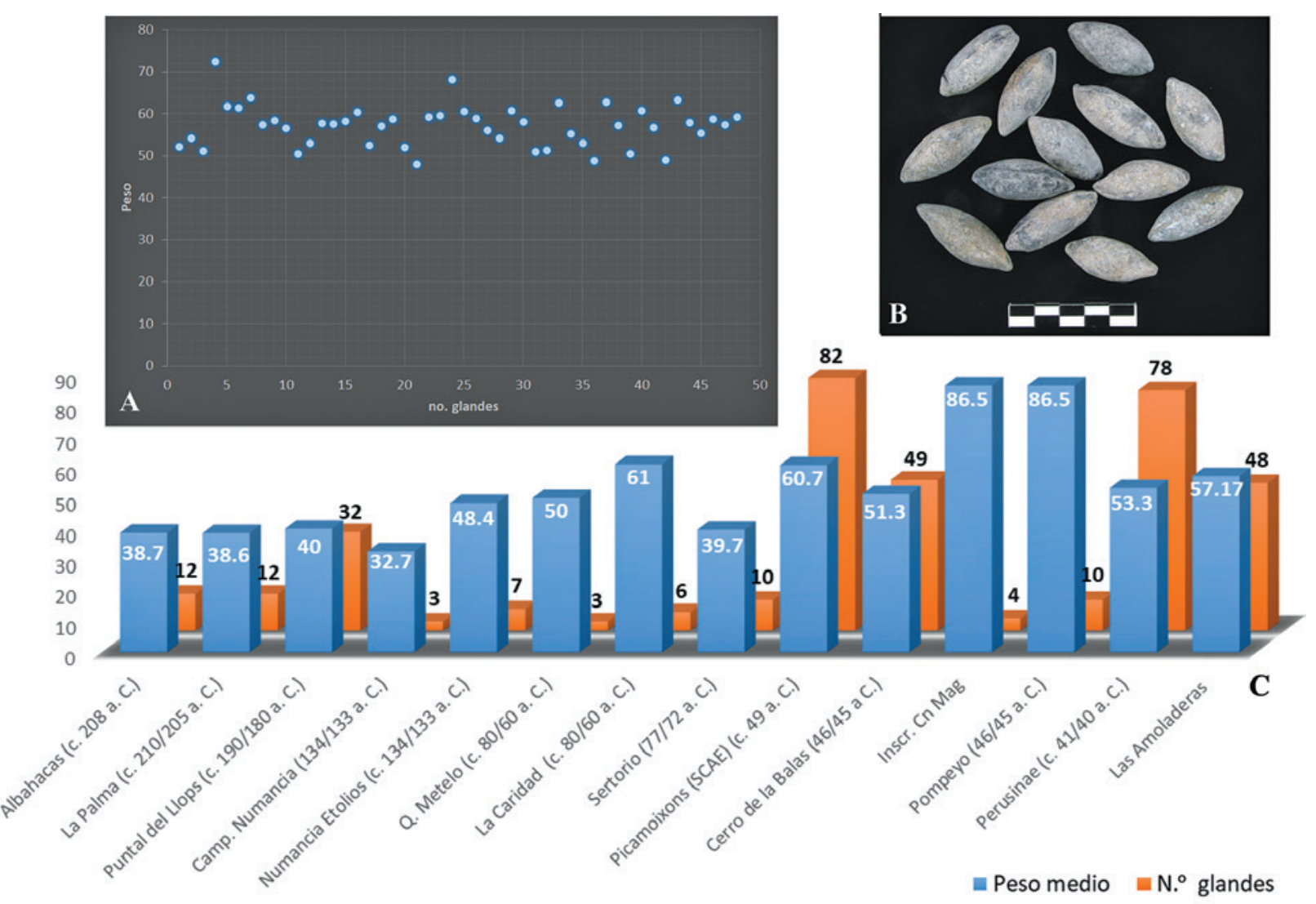

Fig. 10. Glandes plumbeae: A) peso de los 48 glandes de Las Amoladeras; B) selección de algunos glandes de Las Amoladeras; C) evolución de pesos medios de glandes hispanos procedentes de distintos yacimientos (ss. III-I a. C.), incluidos los de Las Amoladeras (imagen B cortesía del ARQVA; A y C elaboradas a partir de Quesada et al., 2015: fig. 18 y tab. 19).

\begin{tabular}{|c|c|c|c|c|c|c|c|c|}
\hline ОвЈЕTо & ${ }^{206} \mathrm{P}_{\mathrm{B}} /{ }^{207} \mathrm{~PB}$ & $\sigma$ & ${ }^{208} \mathrm{P}_{\mathrm{B}} /{ }^{206} \mathrm{P}_{\mathrm{B}}$ & $\sigma$ & ${ }^{206} \mathrm{P}_{\mathrm{B}} /{ }^{204} \mathrm{P}_{\mathrm{B}}$ & $\sigma$ & ${ }^{200} \mathrm{P}_{\mathrm{B}} /{ }^{204} \mathrm{P}_{\mathrm{B}}$ & ${ }^{208} \mathrm{P}_{\mathrm{B}} /{ }^{204} \mathrm{P}_{\mathrm{B}}$ \\
\hline tubería & 1.16794 & 0.00004 & 2.10501 & 0.00024 & 18.23762 & 0.00005 & 15.61523 & 38.39033 \\
\hline plomo & 1.18220 & 0.00004 & 2.09265 & 0.00023 & 18.50939 & 0.00005 & 15.65671 & 38.73371 \\
\hline lingote & 1.19409 & 0.000004 & 2.08502 & 0.00006 & 8.69527 & 0.00006 & 15.65651 & 38.97998 \\
\hline
\end{tabular}

FIG. 11. Valores isotópicos de los objetos analizados. 

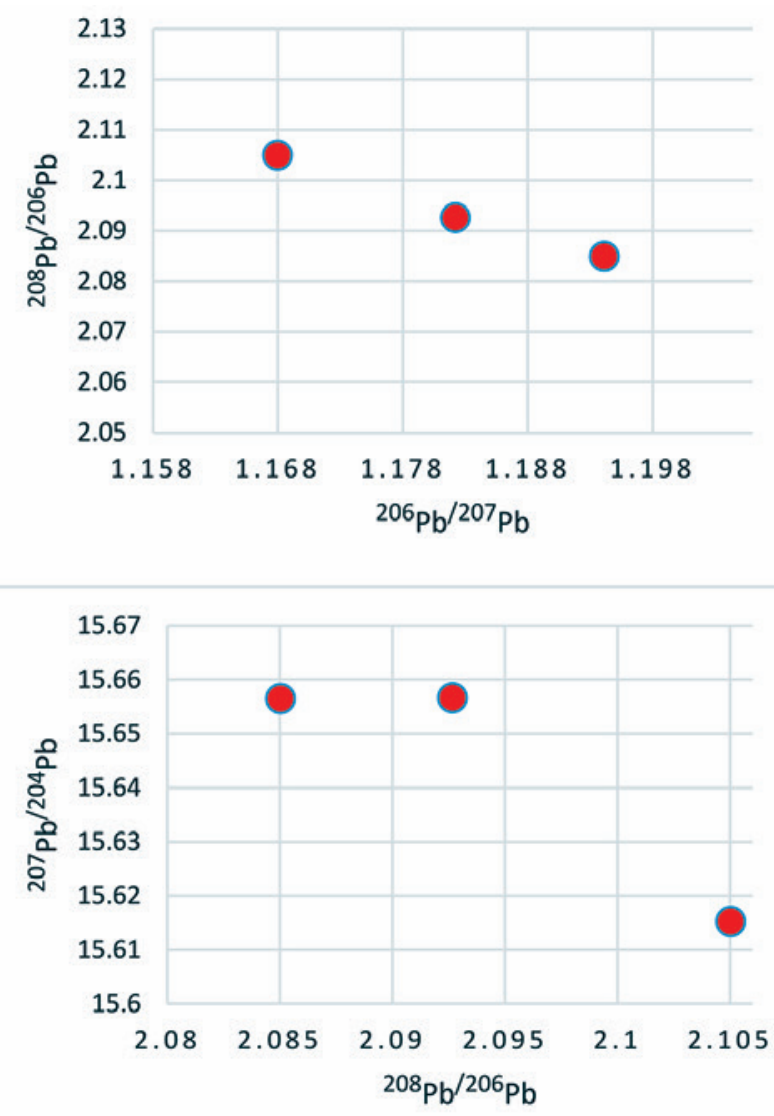
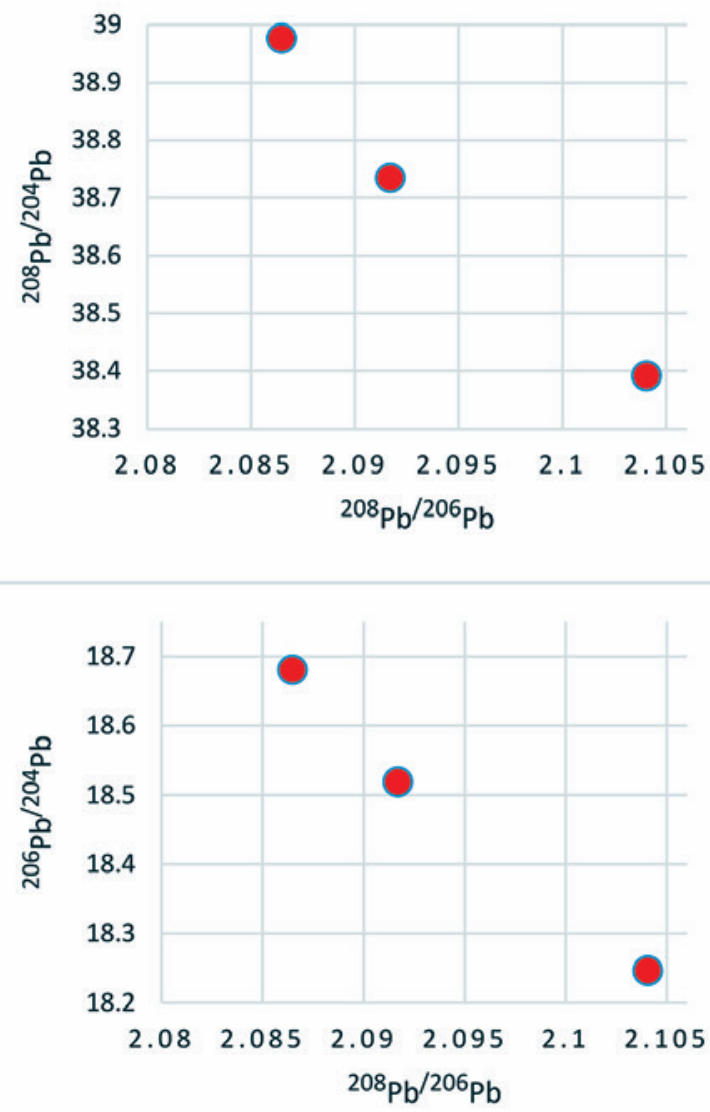

FIG. 12. Mapas isotópicos de los materiales analizados a partir de los valores presentados en la Fig. 11.

una cantidad de plomo de entre 100 y $500 \mu \mathrm{g}$ de la muestra, y posiblemente separarla de otros elementos presentes, a través de un paso en microcolumnas que contienen una resina de plomo específica-TrisKem, Bruz, F-. Con MC-ICP-MS, se puede lograr una precisión superior al $0.001 \%$. En estos análisis, la precisión interna $-2 \sigma-$ de las relaciones isotópicas ${ }^{206} \mathrm{~Pb} /{ }^{207} \mathrm{~Pb}$ y ${ }^{208} \mathrm{~Pb} /{ }^{206} \mathrm{~Pb}$ fue calculada sobre el promedio de $60 \mathrm{va}-$ lores adquiridos para la misma medida $-\leq 40$ ppm-. El contenido de estańo de los objetos analizados se midió con un espectrómetro de masa con plasma acoplado inductivamente -ICP-MS- (Fig. 15).

\subsection{Resultados}

La Fig. 11 proporciona los valores isotópicos de las muestras analizadas. Las relaciones entre los diversos isótopos se utilizan para caracterizar las piezas objeto de estudio. Posteriormente se compararán con una base de datos que incluye la caracterización isotópica de minerales de plomo, de procedencia cierta y que han sido extraídos de diversas áreas mineras del Mediterráneo, activas en la Antigüedad. El objetivo es evaluar el origen del metal con el que se elaboraron los objetos estudiados ${ }^{14}$. La Fig. 12 presenta cuatro mapas isotópicos distintos que proyectan y comparan las ratios de los principales isótopos de plomo, ${ }^{208} \mathrm{~Pb},{ }^{207} \mathrm{~Pb},{ }^{206} \mathrm{~Pb}$ y ${ }^{204} \mathrm{~Pb}$, de las tres

14 Para ello se ha utilizado la base de datos ARCHAEO_ TRACE, que incorpora datos de 3.500 muestras de mineral. Esta base de datos se apoya a su vez en la Oxford Archaeological Lead Isotope Database del Isotrace Laboratory -OXALID- y se ha completado con datos procedentes de la literatura publicada sobre el tema. Una síntesis sobre los estudios que han caracterizado isotópicamente muestras de mineral procedentes de la Península Ibérica en Montero (2018: 316-317). 
muestras analizadas sobre los ejes $\mathrm{x}$ e y de un plano cartesiano. Este tipo de representación nos permite tener una visión bidimensional de los resultados ofrecidos en la Fig. 11 y puede ayudarnos a interpretarla. Normalmente, la información más precisa nos es transmitida por las relaciones isotópicas que incluyen los isótopos de plomo ${ }^{208} \mathrm{~Pb},{ }^{207} \mathrm{~Pb}$ y ${ }^{206} \mathrm{~Pb}$, por lo que en la literatura el gráfico más común es aquel que compara las ratios del ${ }^{206} \mathrm{~Pb} /{ }^{207} \mathrm{~Pb}$ vs. ${ }^{208} \mathrm{~Pb} /{ }^{206} \mathrm{~Pb}$. Sin embargo, tener presentes diferentes combinaciones puede ayudarnos a la hora de interpretar las muestras y cómo se relacionan entre ellas, por lo que también hemos incluido en la Fig. 12 los gráficos comparando ${ }^{208} \mathrm{~Pb} /{ }^{206} \mathrm{~Pb}$ vs. ${ }^{208} \mathrm{~Pb} /{ }^{204} \mathrm{~Pb},{ }^{208} \mathrm{~Pb} /{ }^{206} \mathrm{~Pb}$ vs. ${ }^{207} \mathrm{~Pb} /{ }^{204} \mathrm{~Pb}$ $\mathrm{y}{ }^{208} \mathrm{~Pb} /{ }^{206} \mathrm{~Pb}$ vs. ${ }^{206} \mathrm{~Pb} /{ }^{204} \mathrm{~Pb}$. El resultado es uniforme en todos los casos y nos indica que el plomo de las tres muestras tiene ratios isotópicas muy distintas. Una vez que se ha evaluado la relación entre los distintos objetos, el siguiente paso es aproximarnos a su origen geográfico.
Las Figs. 13 y 14 son dos mapas isotópicos que proyectan las ratios del ${ }^{206} \mathrm{~Pb} /{ }^{207} \mathrm{~Pb}$ contra el ${ }^{208} \mathrm{~Pb} /{ }^{206} \mathrm{~Pb}$, del ${ }^{208} \mathrm{~Pb} /{ }^{204} \mathrm{~Pb}$ y el ${ }^{206} \mathrm{~Pb} /{ }^{204} \mathrm{~Pb}$ de las tres muestras analizadas. En ambas figuras se han añadido, como es habitual, los datos isotópicos existentes para los principales cuerpos minerales en España y de los que se extrajo plomo en la antigüedad: la Sierra de Cartagena (Cartagena/Mazarrón), Sierra Morena y la Sierra de Almagrera (Almería), entre otros. Un factor importante a la hora de evaluar si el objeto estudiado se ha llevado a cabo a partir del reciclaje o no de otros objetos plúmbeos es su porcentaje en estaño. Este aparece de forma natural y como un elemento traza en minas de galena, normalmente en porcentajes inferiores al 0,01\%, siendo la excepción algunas minas catalanas en donde valores de hasta $0,08 \%$ han sido documentados. Como nuestros análisis no sugieren que el plomo utilizado en los objetos estudiados provenga de esta zona, no cabría esperar valores superiores al 0,01\%.

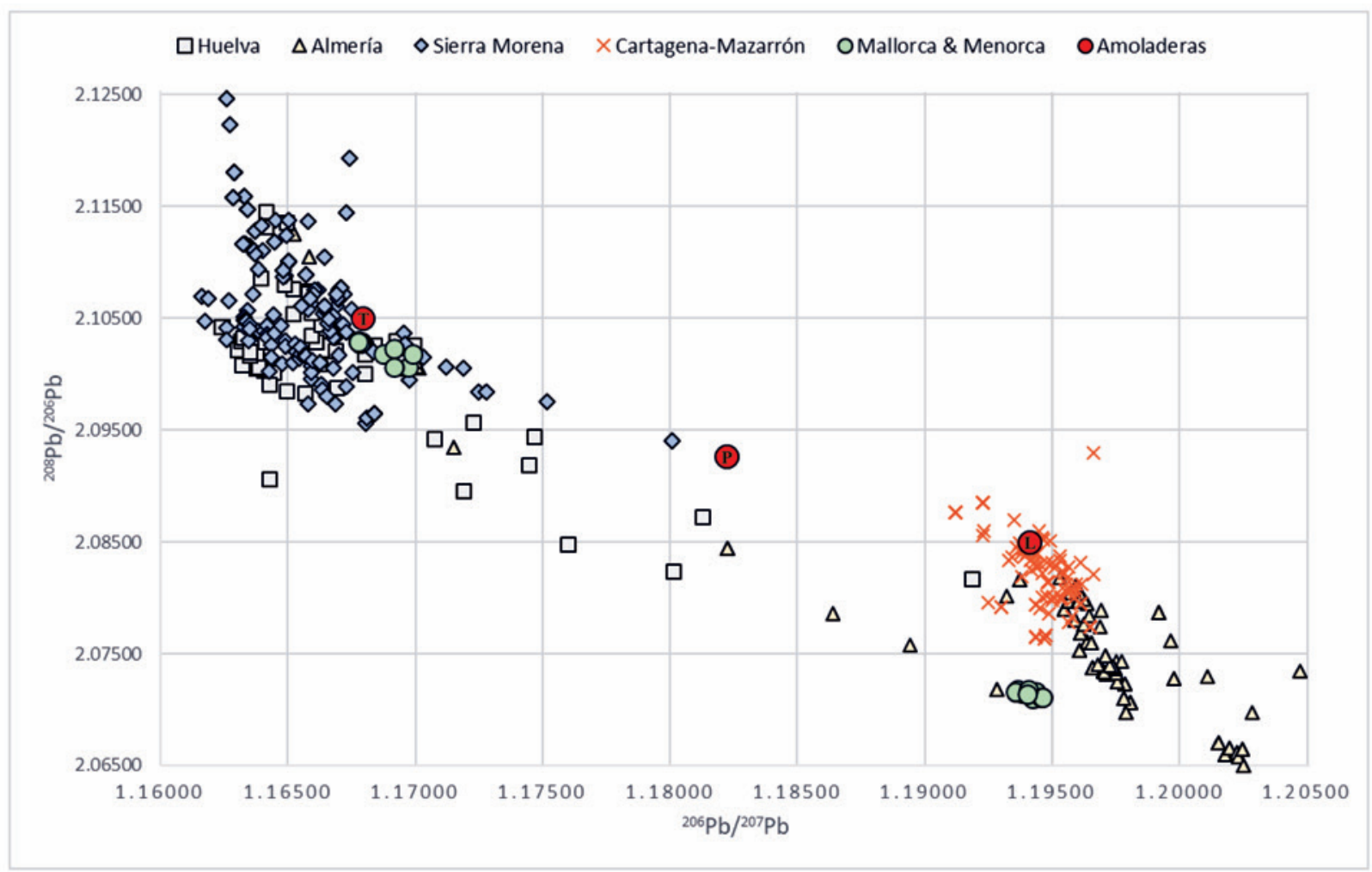

FIG. 13. Diagrama binario con las ratios de los isótopos ${ }^{206} \mathrm{~Pb}{ }^{207} \mathrm{~Pb} y^{208} \mathrm{~Pb}{ }^{206} \mathrm{~Pb}$, de las tres muestras analizadas: $T=$ tuberia; $P$ $=$ plomo L $=$ lingote. 


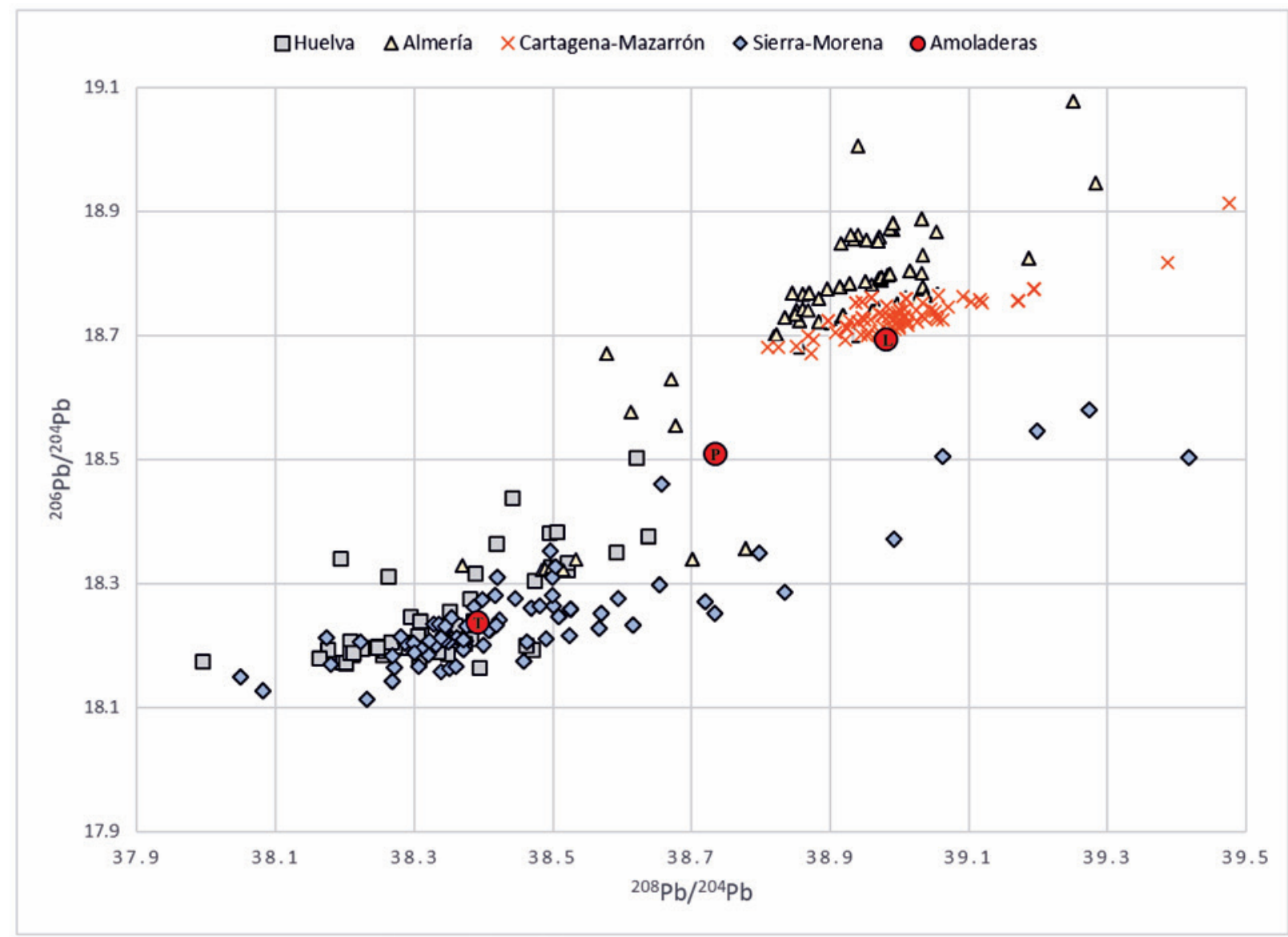

Fig. 14. Diagrama binario con las ratios de los isótopos de ${ }^{208} \mathrm{~Pb}{ }^{204} \mathrm{~Pb} y^{206} \mathrm{~Pb}{ }^{04} \mathrm{~Pb}$, de las tres muestras analizadas.

Esta teoría la refuerzan los análisis químicos realizados sobre lingotes de plomo romanos obtenidos directamente a partir de la fundición de galena. Los resultados muestran una pauta consistente en la que el porcentaje de estaño es muy bajo $\leq 0,01 \%$ (Wyttenbach y Schubiger, 1973; Domergue et al., 1974: 136).

En consecuencia, los objetos plúmbeos con niveles altos de estaño normalmente nos indican que son el resultado del reciclaje de otros objetos -en la mayoría de los casos de tuberías y canalizacionesy que se manufacturaron utilizando soldaduras de plomo ricas en estaño (Gomes et al., 2016). Una vez que estos objetos se vuelven a fundir para su posterior reciclaje, se combinan tanto objetos con plomo y estaño como los que solo contenían plomo, dando como resultado una mezcla en la que el estaño está siempre presente. Un buen ejemplo de estas prácticas se ha documentado en la ciudad de Pompeya en donde la mayoría de tuberías de agua analizadas responden a la práctica del reciclaje (Monteix y Rosso, 2008: 444-446). Por lo tanto, y siguiendo a Gomes et al. (2017: 150), todos los objetos de plomo estudiados en este trabajo que presenten un contenido de estaño superior al $0,01 \%$ se considerarán como resultado del reciclaje. Teniendo en cuenta todo lo anterior, a continuación, pasamos a interpretar la procedencia del metal de las tres muestras analizadas.

La tubería de plomo -T- se agrupa con las lecturas isotópicas de los minerales de Sierra Morena (Figs. 13 y 14), por lo que el origen del plomo utilizado en su elaboración no ofrece dudas y parece que se puede atribuir a dicha zona minera. Si tenemos 
presentes los porcentajes de estańo detallados en la Fig. 15, los valores inferiores a $0.01 \%$ parecen apuntar que no estamos ante un plomo que haya sido reciclado previamente. Este hecho resulta interesante puesto que contrasta con la información procedente de otros yacimientos mencionados anteriormente (Monteix y Rosso, 2008: 444-446; Gomes et al., 2016), pero para el que encontramos un paralelo en las tuberías utilizadas en las termas de Ca l'Arnau en Cabrera de Mar. En este yacimiento, el plomo utilizado en la elaboración de las canalizaciones tampoco parece que se hubiese reciclado previamente (Sinner et al., 2020: 5-8).

El lingote de plomo $-\mathrm{L}-$ presenta unas ratios isotópicas comparables a las del mineral de Cartagena-Mazarrón. La adscripción de lingotes de plomo sellados por miembros de las principales familias mineras de Carthago Nova a las minas de Cartagena-Mazarrón (Domergue et al., 2012) es un hecho probado y, por consiguiente, refuerza la atribución isotópica. Además, como hemos visto anteriormente, el estudio onomástico del resello presente en el lingote puede ponerse en relación con la actividad minera de los Minucii en Cartagena-Mazarrón (Díaz Ariño, 2006: 293-294). Por todo ello, no hay razón para dudar de esta atribución que parece clara (Figs. 13 y 14). Como cabría esperar al tratarse de un lingote, los valores de estaño en la figura 15 son bajísimos.

El plomo monetiforme - $\mathrm{P}-$, por el contrario, no parece tener unas ratios isotópicas compatibles con ninguna de las regiones mineras peninsulares que han sido caracterizadas isotópicamente (Figs. 13 y 14). Resulta de gran interés el hecho de que el plomo monetiforme analizado presenta unas ratios isotópicas muy distintas de las obtenidas en las minas de galena de Bunyola, en Mallorca (Heinrich, 2014; Perelló y Llull, 2019) y Capifort y Binifabini, en Menorca (Perelló y Llull, 2019), dejando claro que, si bien la circulación de estos plomos, parece documentarse en las Baleares, especialmente en Mallorca, el plomo utilizado en la elaboración de la pieza analizada no es un producto local (Fig. 13). Si ampliamos la búsqueda más allá del territorio peninsular, los valores de nuestro plomo monetiforme podrían ser compatibles con minerales sardos (Fig. 16). Sin embargo, como dos de nosotros ya han discutido en trabajos anteriores (Stannard et al., 2019: 141-143), hoy no hay suficientes certezas históricas o arqueológicas para defender que las minas de Iglesiente -en el so de Cerdeña- estuviesen en funcionamiento en este momento (Pinarelli et al., 1995: 54), aunque es cierto que hay evidencias de minería de plomo en la isla en etapas anteriores (Lo Schiavo et al., 2005: 164-166). Tampoco tenemos constancia de que los textos clásicos mencionen las minas sardas y la primera prueba definitiva de minería en Cerdeña -lingotes sellados- no aparecerá hasta el s. II d. C., aunque el plomo sardo ya parece documentarse en los mercados durante la época de Augusto (Domergue y Rico, 2018: 197 y 203). Además, casi todos los lingotes recuperados en naufragios en las costas de Cerdeña llevan sellos asociados a Cartagena, siendo estos reemplazados en época imperial por lingotes originarios de Sierra Morena.

A toda esta información hay añadir el hecho de que los valores isotópicos de nuestro plomo se ajustan muy bien a los obtenidos para varios ejemplares adscritos a las series ítalo-béticas que han sido recientemente caracterizadas isotópicamente (Stannard et al., 2019: 136-137, tab. 2). Estas series no son el único caso en el que nos encontramos con valores isotópicos similares a los del plomo analizado dentro de la Península Ibérica. Pardini et al. (2017) llevaron a cabo análisis sobre un importante conjunto de moneda de Ebusus -grupos Campo, VIII, XII, XVIII y XIX-. Si bien muchas de las piezas analizadas se alineaban bien con el clúster formado por Cartagena-Mazarrón (Fig. 17), un importante número de piezas presentaba unas ratios isotópicas cercanas a las de nuestro plomo y a los ya mencionados ejemplares de las series ítalo-béticas. Tras

\begin{tabular}{|l|c|c|}
\hline \multicolumn{1}{|c|}{ Muestra } & Oвjeto & $\% \mathrm{~S}_{\mathrm{N}}$ \\
\hline n. ${ }^{\circ}$ inv. 50.334 & tubería & 0.001 \\
\hline col. priv. & plomo & 0.026 \\
\hline n. ${ }^{\circ}$ inv. 88.122 & lingote & 0.0003 \\
\hline
\end{tabular}

FIG. 15. Porcentajes de estaño en los objetos analizados. 
comparar los datos de nuestras muestras, de los plomos béticos y las monedas de Ebusus con los valores isotópicos de los minerales de los distritos mineros de Mazarrón, Cartagena, Linares, Ossa Morena y el Valle de Alcudia (Fig. 17), es muy probable que todas las muestras del clúster central se correspondan con objetos que mezclan plomo con dos orígenes distintos y en proporciones desiguales, lo que explica que sus valores no sean uniformes y se extiendan entre los clústeres formados por distritos mineros de Cartagena-Mazarrón y Linares, Ossa Morena y el Valle de Alcudia. Otro indicio que apunta a defender esta tesis y que además ayuda a explicar el proceso de manufacturación del plomo monetiforme analizado es su porcentaje de estaño. A diferencia de lo que ocurría con la tubería o el lingote, el plomo monetiforme presenta unos niveles de estaño del 0,026\% (Fig. 15) y superiores a la barrera del $0,01 \%$, lo que permite proponer que la pieza es el producto del reciclaje de objetos de plomo.

A tenor de todo lo anterior, pensamos que la mejor explicación es que el metal utilizado en la elaboración del plomo analizado no proviene de una sola fuente, sino de una mezcla que incorpora plomo de dos distritos mineros distintos: Sierra Morena, más específicamente de Linares, y Cartagena-Mazarrón.

\section{Discusión: función, cronología y ruta del barco}

El cargamento de enseres metálicos documentado en Las Amoladeras, especialmente la presencia de objetos de plomo de funciones muy diversas; su hundimiento en las costas del principal distrito minero del SE peninsular, y la presencia de un lingote

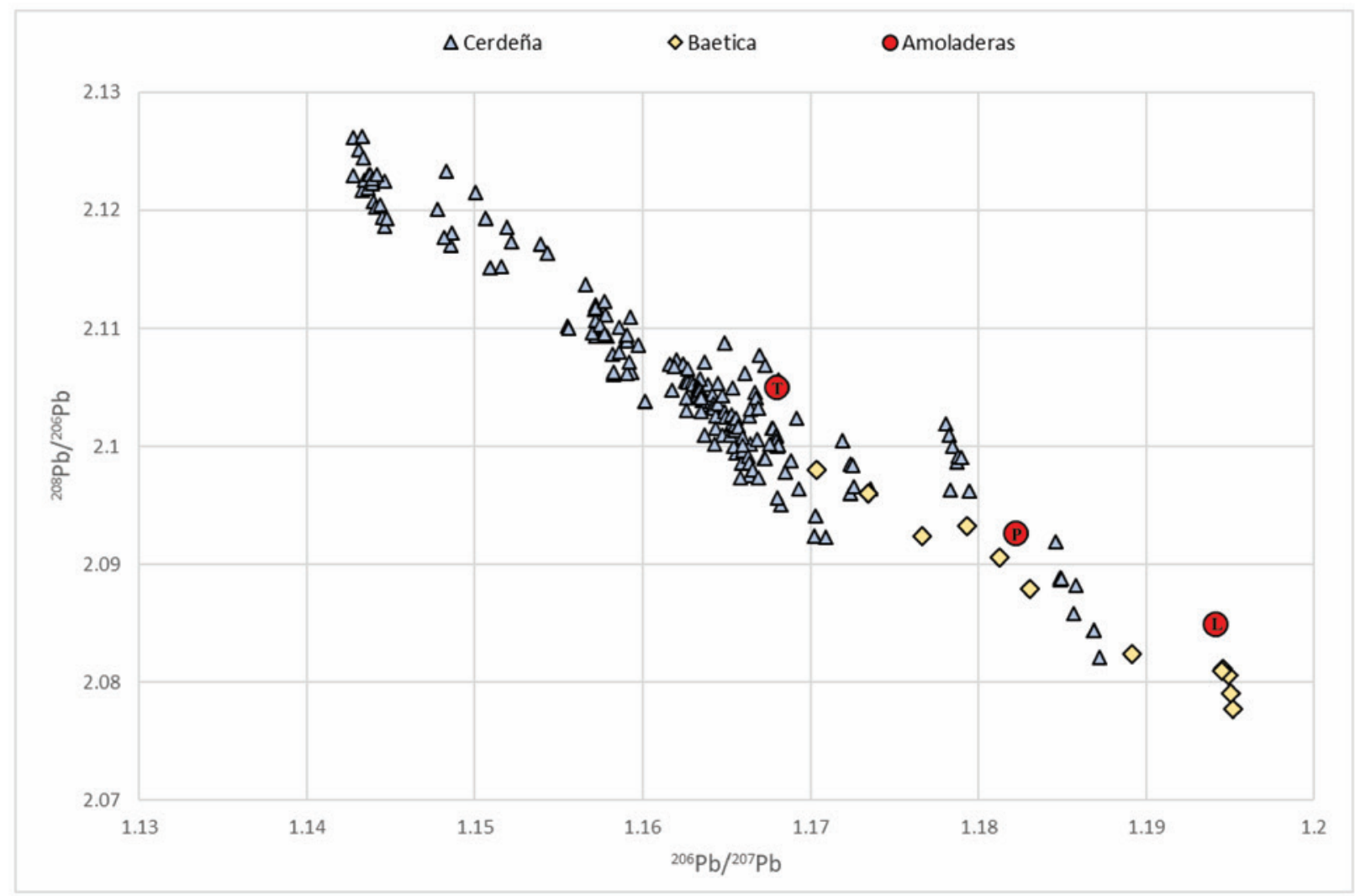

FIG. 16. Diagrama binario con las ratios de los isótopos ${ }^{206} \mathrm{~Pb}{ }^{207} \mathrm{~Pb} y^{208} \mathrm{~Pb}{ }^{206} \mathrm{~Pb}$, de los tres objetos analizados, los plomos béticos (Stannard et al., 2019) y minerales sardos. 


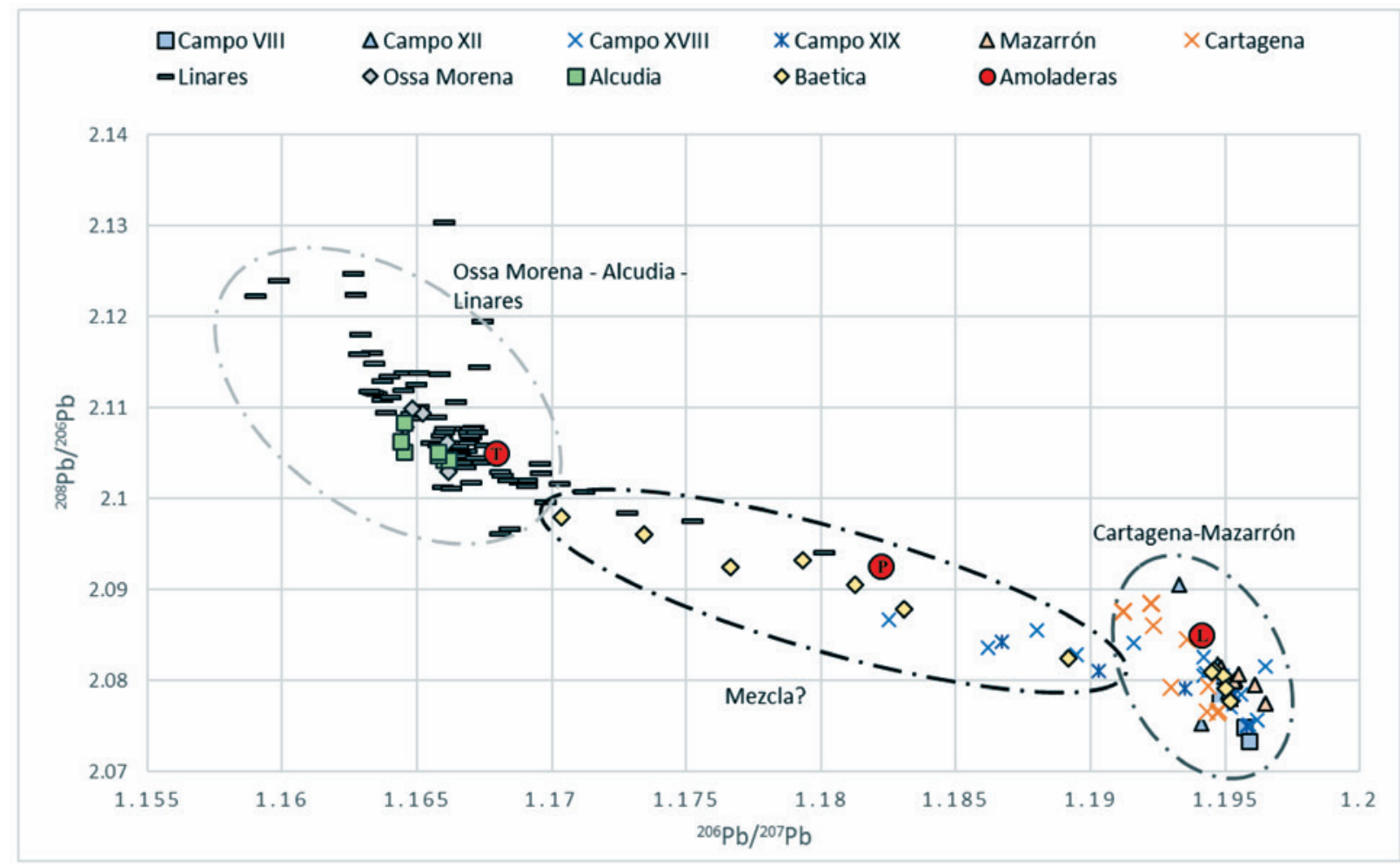

Fig. 17. Diagrama binario con las ratios de los isótopos ${ }^{208} \mathrm{~Pb}{ }^{206} \mathrm{~Pb}$ y ${ }^{206} \mathrm{~Pb}{ }^{07} \mathrm{~Pb}$, de los tres objetos analizados, los plomos béticos (Stannard et al., 2019) y de las monedas de Ebusus (Pardini et al., 2017), además de los valores isotópicos de los minerales de los distritos mineros de Mazarrón, Cartagena, Linares, Ossa Morena y el Valle de Alcudia.

que podemos ubicar epigráfica e isotópicamente como procedente de las minas de Cartagena-Mazarrón, pensamos que permiten proponer que al menos una parte del cargamento del pecio estaba dedicado a transportar plomo para su reciclaje $\mathrm{e}^{15}$. Si estamos en lo cierto, el pecio de Las Amoladeras nos permite documentar la existencia de cargamentos comerciales de plomo, seguramente como carga secundaria, y que no responden al usual transporte de lingotes. Este hecho ayuda a vislumbrar un aspecto de la comercialización del plomo hispano al que se le ha prestado menos atención en la bibliografía científica, pero que cabe pensar que fue cada vez más frecuente a medida que el stock de elementos

15 Los cargamentos heterogéneos están bien documentados siendo el de Comacchio uno de los mejores ejemplos. Transportaba lingotes de plomo hispano, vajilla, ánforas, objetos de bronce y elementos orgánicos como cuero, madera o tejidos (Berti, 1985 y 1987). plúmbeos, especialmente tuberías y canalizaciones, crecía en las ciudades hispanas.

En cuanto a la cronología del navío, el contexto cerámico documentado, aunque escaso, contaba con ánforas de la forma Dressel 1 y Lamboglia 2 (Mas, 1985: 162; Miñano, 2006: 12), que nos sitúan en una cronología tardorrepublicana, muy posiblemente ya en el s. I a. C., pero nunca más allá del 30 a. C., momento en que las ánforas Lamboglia 2 son sustituidas por las Dressel 6 adriáticas (Beltrán Lloris, 1970; Carre, 1985: 211) ${ }^{16}$. Esta cronología

16 Que sepamos no existen dibujos ni imágenes de las ánforas que cita Mas García. Cuando habla de Dressel 1, si se tratase de ánforas del tipo Dressel 1A, su producción finaliza a mediados del s. I a. C. aproximadamente. La Dressel в itálica, por su parte, llega a la última década del s. I a. C., mientras que la Dressel 1c no finaliza su producción hasta el último cuarto del s. I a. C. -sobre este tipo de ánforas y su cronología, Beltrán Lloris, 1970; Peacock, 1971 y 1977; Tchernia, 1986; entre otros-. 
pensamos que puede matizarse aún más a partir de la tipología del lingote de plomo -segunda mitad del s. I a. C.- y del peso de los glandes -muy posiblemente postsertoriano, siendo los conjuntos más similares del 50-40 a. C. (Fig. 10c). Ninguno de estos elementos procura una datación segura para el pecio de Las Amoladeras, pero la combinación de estos sí que permite proponer una cronología entre las décadas 50-30 a. C.

Aunque no es mucho lo que tenemos para reconstruir la ruta del navío, los plomos monetiformes cuya circulación está bien atestiguada en las Islas Baleares, especialmente en Mallorca (Pollentia), y, en menor medida, el importante conjunto de glandes, elemento característico de los honderos baleares y que tanto alaban las fuentes clásicas (Plinio 3.5.76; Estrabón 3.1.2), podrían poner el barco en relación con las Islas Baleares. Por otro lado, el lingote de plomo de Marcus Minucius, así como el lugar de su hundimiento, asocian al navío indudablemente con las costas del sE peninsular y, más en concreto, con la ciudad de Carthago Nova.

La presencia de gentes procedentes de las Islas Baleares en la ciudad está bien documentada en la segunda mitad del s. I a. C., siendo un buen ejemplo la gens Fufii (Poveda, 2000: 299). Además, la participación de romano-itálicos en la industria minera cartagenera, es bien conocida durante el último cuarto del s. I a. C. Quizás el mejor ejemplo es el lingote plúmbeo con cartela SOC•BALIAR procedente del pecio Escombreras III, y que se ha relacionado con una posible Soc(ietas) Baliar(ica), especializada en la explotación o comercialización de plomo en Carthago Nova (Poveda, 2000; Alonso, 2009: 43, especialmente nn. 1 y 50). El pecio de Las Amoladeras, sin duda, debe de situarse en este eje económico que gira en torno a la producción, comercialización y reutilización del plomo entre Carthago Nova, su territorio y las Insulae Baliares ${ }^{17}$.

17 Es posible que la exportación del plomo de otras cuencas mineras, más concretamente de Sierra Morena, se realizase desde el puerto de Carthago Nova (Rodà, 2004: 186; Alonso, 2009: 50). En concreto, el distrito minero de Cástulo (Linares) tenía una buena comunicación con Cartagena a través de la Vía Augusta, dato del que se hace eco el
Sin tener información alguna acerca del resto del cargamento, de las dimensiones o la arquitectura naval del barco, resulta difícil determinar su trayecto o el tipo de navegación que realizaba. Las opciones más plausibles son, en primer lugar, el cabotaje entre Carthago Nova y otro puerto del levante peninsular, siendo buenos candidatos Ilici, Dianum o incluso Valentia. Cabe recordar la presencia de un Q. Fufius que recibió tierras en Ilici en el último tercio del s. I a. C. y al que se clasifica como baliaricus en el reparto centurial. En segundo lugar, un trayecto directo entre Carthago Nova y las Baleares, quizás Pollentia.

La primera opción cuadra bien con la localización costera del pecio y los modelos de redistribución propuestos hasta la fecha (Nieto, 1988 y 1997) y en los que Carthago Nova es el puerto de salida de varias líneas de cabotaje que distribuyen mercancías entre, como mínimo, los cabos de Gata y de la Nao (Alonso, 2009: 18-19). En opinión de Alonso (2009: 39) estamos ante “... la producción de numerosos objetos en fundiciones del distrito minero cartaginés, y que parecen formar parte de un cargamento de redistribución acompañado de ánforas itálicas...”. Esta hipótesis, no obstante, requiere explicar la presencia de cuatro plomos monetiformes cuyo origen cabe localizar en Mallorca. La teoría que mejor explica este fenómeno es que los plomos pertenecían a la bolsa de uno de los pasajeros del barco, quizás un mercator, ya que estos solían navegar con la mercancía (Arévalo y Delgado, 2016: 132). El mercator podría haberse embarcado en el navío de Las Amoladeras, junto con parte de la carga con la que comerciaba, en el puerto de salida al que habría llegado en ruta desde las Islas Baleares.

mismo Estabón (3.4.6). En este contexto, son especialmente relevantes los precintos de plomo con las siglas $S \bullet B \bullet A$, [s?] $A \bullet B A$ y $S \cdot B A$ documentados en la provincia de Badajoz (Antolinos y Díaz Ariño, 2015) y en Córdoba (Domergue, 1971: 350; García Romero, 2002: 342); y $S \bullet A \bullet B$ en La Carolina (Jaén) (Díaz Arińo y Antolinos, 2019: 298), para los que se ha propuesto la pertenencia a una Societas Argentifodinarum Baeticarum (?) o Societas Baetica (?) Argentifodinarum (Antolinos y Díaz Ariño, 2015: 220), pero sin descartarse totalmente la posibilidad de que se trate de la mencionada Soc(ietas) Baliar(ica) (Alonso, 2009: 50). 
Una hipótesis similar ha sido propuesta por Arévalo y Delgado (2016: 131-132) para explicar la heterogénea composición del conjunto numismático recuperado en el pecio de Isla Pedrosa (Stannard, 2005; Stannard y Sinner, 2014: 171-174).

Tampoco se puede descartar una ruta directa entre Carthago Nova y las Baleares - posiblemente Pollentia-, travesía ya conocida durante el final de la Prehistoria y la Protohistoria (Guerrero, 1993) y bien documentada en los textos clásicos (Liv. 23.34.17, 28.37.1-10). La fundición de plomo en las islas está también bien estudiada entre Augusto y el s. i d. C. (Enseñat, 1975: 63-72), por lo que un cargamento de objetos de plomo, como el que parece que transportaba nuestro barco, podría fundirse y utilizarse para el autoconsumo. De hecho, la presencia de plomo procedente de Cartagena ha sido recientemente documentada isotópicamente en objetos recuperados en los yacimientos de Son Espases y Son Real (Perelló y Llull, 2019: 106-107). Los plomos monetiformes analizados podrían ser un ejemplo de este tipo de prácticas. En cualquier caso, solamente nuevos hallazgos y futuros estudios podrán esclarecer dichas cuestiones.

En resumen, tras estudiar el pecio de Las Amoladeras de forma interdisciplinar, pensamos que hay evidencias suficientes para enmarcarlo en un contexto histórico específico, que no es otro que el de la comercialización y reutilización del plomo en la Hispania tardorrepublicana, en general, y entre Carthago Nova, el se peninsular y las Baleares, en particular.

\section{Bibliografía}

ACIP = Villaronga, L. y Benages, J. (2011).

Alonso, D. (2009): "Minería y tráfico marítimo. Pecios y enclaves costeros para el estudio de la actividad minera en Carthago Nova", Argentum, 1, pp. 11-55.

Andreu, J. y Urrizburu, A. (2019): "Praefascinandae res: cuatro nuevos fascina fálicos procedentes del norte de la Tarraconense (Cinco Villas de Aragón, Zaragoza)", Anales de Arqueología Cordobesa, 30, pp. 319-332.
Antolinos, J. A. y Díaz Ariño, B. (2015): "Los precintos de plomo del Museo de Badajoz y la actividad de las compañías mineras romanas en el sur de Hispania a comienzos de época imperial", Madrider Mitteilungen, 56, pp. 211-231.

Arévalo, A. y Delgado, F. J. (2016): "Las monedas y su propietario. Dinero de bolsillo en una pequeńa embarcación”. En Buxó, R. (coord.): Illa Pedrosa. Comerç maritim i xarxes de redistribució en època tardorepublicana al Mediterrani centreoccidental. Girona: Museu d'Arqueologia de Catalunya-Centre d'Arqueologia Subaquàtica de Catalunya, pp. 118-132.

Arévalo, A. y Moreno, H. (2017): "La moneda y el trasiego portuario. Una mirada desde la costa atlántica del sur de Hispania". En Campos, J. M. y BermeJo, J. (eds.): Los Puertos Atlánticos Béticos y Lusitanos y su relación comercial con el Mediterráneo. Huelva: Univ. de Huelva, pp. 171-203.

Beltrán Lloris, M. (1970): Las ánforas romanas en España. Zaragoza: Institución Fernando el Católico.

Bernal, D. (2010): "Fishing Tackle in Hispania: Reflections, Proposals and First Results”. En BekkerNielsen, T. y Bernal, D. (eds.): Ancient nets and fishing gear. Proceedings of the International Workshop on Nets and Fishing Gear in Classical Antiquity: a first approach (Cádiz, November, 15-17, 2007). CádizAarhus: Univ. de Cádiz, pp. 83-139.

Berti, F. (1985): "La nave romana di Comacchio", $R i-$ vista di Studi Liguri, 51, pp. 553-570.

Berti, F. (1987): "L'Epave aux lingots de Valle Ponti (Comacchio)". En Chevalier, R. (ed.): Les mines et la métallurgie en Gaule et dans les provinces voisines, Caesarodunum, 22, pp. 129-136.

Blay, J. (2004): "Monedas votivas en el pie de mástil de navíos romanos", Gaceta Numismática, 155, pp. 5-13.

Carlson, D. N. (2007): "Mast-Step Coins among the Romans", International Journal of Nautical Archaeology, 36 (2), pp. 317-324.

Carre, M.-B. (1985): "Les amphores de la Cisalpine et de l'Adriatique au début de l'Empire", Mélanges de l'École Française de Rome. Antiquité, 97 (1), pp. 207245.

Casariego, A.; Cores, G. y Pliego, F. (1987): Catálogo de plomos monetiformes de la Hispania Antigua. Madrid: Artis Traditio.

Cerezo, F. (2015): “Comercialización de los lingotes de plomo de Carthago Nova en el periodo tardorrepublicano. Análisis espacial y rutas marítimas”. En López Ballesta, J. M. (coord.): PHICARIA. III Encuentros 
Internacionales del Mediterráneo. Minería y metalurgia en el Mediterráneo y su periferia oceánica (Mazarrón, 2014). Mazarrón: Univ. Popular de Mazarrón, pp. 182-207.

Colls, D.; Domergue, C. y Guerrero, V. (1986): "Les lingots de plomb de l'épave Cabrera 5 (île de Cabrera, Baléares)", Archaeonautica, 6, pp. 31-80.

Crawford, M. H. (1974): Roman Republican Coinage. Cambridge: cup.

Díaz Ariño, B. (2006): "Sello sobre lingote de plomo inédito conservado en el Museo Nacional de Arqueología Marítima de Cartagena”, Salduie, 6, pp. 291295.

Díaz Ariño, B. y Antolinos, J. A. (2013): “The Organization of Mining and Metal Production in Carthago Nova between the late Republic and Early Empire", Athenaeum, 101 (2), pp. 535-553.

Díaz Ariño, B. y Antolinos, J. A. (2019): "Roman Mining Companies in Spain”, Zeitschrift für Papyrologie und Epigraphik, 210, pp. 291-303.

Domergue, C. (1971): "El Cerro del Plomo: mina El Centenillo (Jaén)”, Noticiario Arqueológico Hispánico, 16 , pp. 267-381.

Domergue, C. (1987): Catalogue des mines et fonderies de la Peninsule Ibèrique. Madrid: Casa de Velázquez.

Domergue, C. (1994): "Production et commerce des métaux dans le monde romain: l'exemple des métaux hispaniques d'après l'épigraphie des lingots". En $A c$ tes de la VIIe Rencontre franco-italienne sur l'épigraphie du monde romain (Rome, 1992). Roma: EFR, pp. 6191.

Domergue, C. (1998): “A view of Baetica's external commerce in the $1^{\text {st }}$ c. A.D. based on its trade in metal”. En Keay, S. (ed.): The Archaeology of Early Roman Baetica. Journal of Roman Archaeology Suppl., 29. Portsmouth, pp. 201-214.

Domergue, C.; Laubenheimer, F. y Liou, B. (1974): "Les lingots de plomb de L. Carulius Hispallus", Revue Archéologique de Narbonnaise, 7, pp. 119-137.

Domergue, C. y Mas García, J. (1983): "Nuevos descubrimientos de lingotes de plomo romanos estampillados". En Crónica del XVI Congreso Arqueológico Nacional (Murcia-Cartagena, 1982). Zaragoza: Univ. de Zaragoza, pp. 905-912.

Domergue, C.; Quarati, P.; Nesta, A. y Trincherini, P. R. (2012): "Retour sur les lingots de plomb de Comacchio (Ferrara, Italie) en passant par l'archéométrie et l'épigraphie". En Orejas, A. y Rico, C. (eds.): Minería y metalurgia antiguas. Visiones y revisiones.
Homenaje a C. Domergue. Madrid: Casa de Velázquez, pp. 81-103.

Domergue, C. y Rico, C. (2018): "L'approvisionnement en métaux de l'Occident méditerranéen à la fin de la République et sous le Haut-Empire. Flux, routes, organisation". En Woyтeк, B. (dir.): Infrastructure and Distribution in Ancient Economies. Viena: AASP, pp. 193-252.

Enseñat, C. (1975): "Las plaquetas de plomo mallorquinas (sistematización tipológica)", Mayurqa, 14, pp. 63-117.

García-Bellido, M. P. (1986): "Nuevos documentos sobre minería y agricultura romanas en Hispania", Archivo Español de Arqueología, 59, pp. 13-46.

García-Bellido, M. P. (2001): "Plomos monetiformes con el topónimo ibérico de Gador", Palaeohispanica, 1, pp. 335-340.

García del Toro, J. R. (1997-1998): "Los hábitats neo-eneolíticos de Las Amoladeras y de Calblanque en Cabo de Palos treinta años después: Nuevas perspectivas de futuro y 'puesta en valor'", Anales de Prehistoria y Arqueologia, 13-14, pp. 301-316.

García Romero, J. (2002): El papel de la minería y la metalurgia en la Córdoba romana. Córdoba: Universidad de Córdoba.

García Roselló, J.; Martín Menéndez, A. y Cela, X. (2000): "Nuevas aportaciones sobre la romanización en el territorio de Iluro (Hispania Tarraconensis)", Empúries, 52, pp. 29-54.

Gomes, S. S.; Araújo, M. F.; Soares, A. M. M. y CoRREIA, V. H. (2017): "Provenance evidence for Roman lead artefacts of distinct chronology from Portuguese archaeological sites", Journal of Archaeological Science, 16, pp. 149-156.

Gomes, S. S.; Valério, P.; Alves, L. C.; Araújo, M. F. y Soares, A. M. M. (2016): "Tin determination in fistula seals from Conimbriga and Augusta Emerita", Microchemical Journal, 125, pp. 540-546.

GowLand, W. (1901): "The Early Metallurgy of Silver and Lead: Part I, Lead", Archaeologia, 57 (2), pp. 359-422.

Guerrero, V. M. (1993): Navios y navegantes en las rutas de Baleares durante la Prehistoria. Palma de Mallorca: El Tal.

Guillén, M. C. (1999): Las monedas de plomo de Susaña (Mazarrón), un modelo de acuñación minera en la Hispania Antigua. Mazarrón: Univ. Popular de Mazarrón.

Guitart i Duran, J. (2007): "L'utilisation de l'eau en Catalogne romaine: le cas de Iesso (Guissona)". En 
Brun, J. y Fiches, J. L. (eds.): Enérgie hydraulique et machines élévatrices d'eau dans l'Antiquité. Actes Colloque International Vers-Pont-du-Gard. Pont du Gard: Centre Jean Bérard, pp. 7-22.

Heinrich, M. (2014): "Avances en el estudio histórico de la mina de galena de Bunyola (isla de Mallorca)", Saguntum, 46, pp. 189-200.

Hoyo, J. del y VÁzquez Hoys, A. M. (1996): "Clasificación funcional y formal de amuletos fálicos en Hispania", Espacio, Tiempo y Forma. Serie II. Historia Antigua, 9, pp. 441-466.

Jáuregui y Gil-Delgado, J. J. (1948): "Exploraciones submarinas en Cartagena y San Pedro del Pinatar", Archivo Español de Arqueología, 21, pp. 38-47.

Lo Schiavo, F.; Giumlia-Muir, A.; Sanna, U. y ValeRA, R. (2005): Archaeometallurgy in Sardinia. Monographies Instrumentum, 30. Montagnac.

Marín Jordá, C. y Ribera i Lacomba, A. (2009): "Las termas republicanas de l'Almoina", Quaderns de Difusió Arqueológica, 7, pp. 9-39.

Martínez Chico, D. (2019): "Tesserae frumentariae, nummariae et 'spintriae' Hispaniae. Hallazgos y nuevas perspectivas", Revue Numismatique, 176, pp. 107-138.

Mas García, J. (1979): El puerto de Cartagena. Rasgos geográficos e históricos. Su tráfico marítimo en la Antigüedad. Cartagena: Junta Corp. Puerto de Cartagena.

Mas García, J. (1985): "El polígono submarino de Cabo de Palos. Sus aportaciones al estudio del tráfico marítimo antiguo". En VI Congreso Internacional de Arqueología Submarina (Cartagena, 1982). Cartagena: Subdirección General de Arqueología y Etnografía, pp. 153-171.

Miñano, A. I. (2006): "Los fondos museográficos del Museo Nacional de Arqueología Marítima. Las Amoladeras", Cuadernos de Arqueologia Marítima, 7, pp. 8-15.

Monteix, N. y Rosso, E. (2008): “L'artisanat du plomb à Pompéi", Mélanges de l'École Française de Rome, 120 (1), pp. 241-247.

Montero, I. (2018): "La procedencia del metal: consolidación de los estudios con isótopos de plomo en la Península Ibérica", Revista d'Arqueologia de Ponent, 28, pp. 313-330.

Nicolás, J. C. de y Obrador, B. (2017): "Novetats epigràfiques menorquines II", Sylloge Epigraphica Barcinonensis, 15, pp. 161-172.

NiEto, X. (1988): "Cargamento principal y cargamento secundario", Cahiers d'Histoire, 33 (3-4), pp. 379395.
Nieto, X. (1997): "Le commerce de cabotage et de redistribution". En Pomey, P. (dir.): La Navigation dans l'Antiquité. Aix-en-Provence: Édisud, pp. 146-159.

Pardini, G.; Nisi, S.; Ferrante, M.; Di Vacri, M. L. y Trincherini, P. R. (2017): "Precise lead isotope ratios measurements on Ebusus coins and on some Campanian imitations". En Proceedings $3^{\text {rd }}$ Imeko International Conference on Metrology for Archaeology and Cultural Heritage (2017). Lecce: MetroArchaeo, pp. 666-669.

Peacock, D. P. S. (1971): "Roman amphorae in pre-Roman Britain”. En Hill, D. y Jesson, M. (eds.): The Iron Age and its Hill-Forts. Papers presented to Sir Mortimer Wheeler on the occasion of his eightieth year. Southampton: suAs, pp. 161-188.

Peacock, D. P. S. (1977): "Recent discoveries of Roman amphora kilns in Italy", The Antiquaries Journal, 57 (2), pp. 262-269.

Perelló, L. y Llull, B. (2019): “Circulación y consumo de plomo en las Islas Baleares durante la Edad del Hierro. Nuevos datos isotópicos de galenas y metales arqueológicos", Zephyrus, Lxxxıv, pp. 89-113.

Pinarelli, L.; Salvi, D. y Ferrara, G. (1995): “The sources of ancient Roman lead, as deduced from lead isotopes: the ingots from the Mal di Ventre wreck (Western Sardinia, Italy)", Science and Technology for Cultural Heritage, 4 (1), pp. 79-86.

Pinedo, J. (1996): "Inventario de yacimientos arqueológicos subacuáticos del litoral murciano", Cuadernos de Arqueología Maritima, 4, pp. 57-90.

Poveda, A. M. (2000): "Societas Baliarica. Una nueva compañía minera romana de Hispania”, Gerión, 18, pp. 293-313.

Quesada, F.; Gómez, F.; Molinos, M. y Bellón, J. P. (2015): "El armamento hallado en el campo de batalla de Las Albahacas-Baecula". En Belión, J. P.; Ruiz, A.; Molinos, M.; Rueda, C. y Gómez, F. (eds.): La Segunda Guerra Púnica en la Peninsula Ibérica. Baecula, arqueología de una batalla. Jaén: Univ. de Jaén, pp. 311-394.

Rico, C. (2010): "Sociétés et entrepreneurs miniers italiques en Hispanie à la fin de l'époque républicaine. Une comparaison entre les districts de Carthagène et de Sierra Morena", Pallas, 82. Ab Aquitania in Hispaniam. Mélanges d'Histoire et d'Archéologie offerts à P. Sillières, pp. 359-415.

Rico, C. (2011): "Réflexions sur le commerce d'exportation des métaux à l'époque romaine. La logique du stockage". En Arce, J. y Goffaux, B. (eds.): Horrea 
d'Hispanie et de la Méditerranée romaine. Madrid: Casa de Velázquez, pp. 41-64.

RodÀ, I. (2004): “Agripa y el comercio del plomo", Mastia, 3, pp. 183-193.

Rodríguez Gavilá, G. (2017): "Plomos monetiformes con leyenda N. Caleci”, Hécate, 4, pp. 76-85.

Rostovtzeff, M. I. (1903): Tesserarum Urbis Romae et Suburbi Plumbearum Sylloge. Commissionnaires de l'Académie Impériale des Sciences, Supl. de 1905. San Petersburg.

RRC = CRAWFORD, M. H. (1974).

Sabaté, V. (2017): "Revisión de algunos epígrafes ibéricos de las Baleares", Palaeohispanica, 17, pp. 195-205.

Sáenz, J. C. y Lasuén, M. D. (2004): "El amuleto fálico de oro de Bilbilis (Calatayud-Zaragoza)", Salduie, 4, pp. 221-227.

Sinner, A. G.; Ferrante, M.; Nisi, S. y TrincheriNI, P. R. (2020): "Lead isotopic evidence of lead supply in ancient Ilduro (second-first centuries BCE)", Archaeological and Anthropological Science, 12 (131), pp. 1-20.

Sinner, A. G. y Velaza, J. (2018): "Epigraphy: The Palaeohispanic Languages". En SмIтH, C. (ed.): Encyclopedia of Global Archaeology. Cham: Springer Intern. Pub., pp. 1-13.

Sinner, A. G. y Velaza, J. (eds.) (2019): Palaeohispanic Languages and Epigraphies. Oxford: oup.

Stannard, C. (2005): "Numismatic Evidence for Relations between Spain and Central Italy at the Turn of the Second and First Centuries вс", Revue Suisse de Numismatique, 84, pp. 47-79.

Stannard, C. y Sinner, A. G. (2014): "A Central Italian coin with Dionysus/panther types, and contacts between Central Italy and Spain, in the 2nd and 1st centuries BC", Saguntum, 46, pp. 159-180.
Stannard, C.; Sinner, A. G. y Ferrante, M. (2019): "Trade between Minturnae and Hispania in the Late Republic. A Comparative Analysis of the Minturnaean Lead Issues and the Spanish Plomos Monetiformes of the Italo-Baetican Series, and the Numismatic and Epigraphic Evidence of the Trade", Numismatic Chronicle, 179, pp. 123-171.

Stannard, C.; Sinner, A. G.; Moncunil, N. y Ferrer, J. (2017): "A plomo monetiforme from the Iberian settlement of Cerro Lucena (Enguera, Valencia) with a north-eastern Iberian legend, and the Italo-Baetican series", Journal of Archaeological Numismatics, 7, pp. 59-106.

TChernia, A. (1986): Le vin de l'Italie romaine. Roma: École Française de Rome.

Trilla, E. y Calero, A. (2008): "Los plomos monetiformes de época romana en la isla de Mallorca", Acta Numismàtica, 38, pp. 55-85.

Trincherini, P. R. y Facchetti, S. (1983): "Isotope Dilution Mass Spectrometry applied to lead determination". En FACCHETTI, S. (ed.): Analytical techniques for heavy metals in biological fluids. Ámsterdam: Elsevier, pp. 255-272.

VARGAS, J. M. (2013): "La pesca a bordo en la Antigüedad. Aproximación a través del instrumental pesquero de Arqua (Cartagena, Murcia)". En Nieto, X.; Ramírez, A. y Recio, P. (coords.): I Congreso de Arqueología Náutica y Subacuática Española (Cartagena, 2013). Cartagena: Univ. de Cádiz, pp. 160-178.

Villaronga, L. y Benages, J. (2011): Ancient Coinage of the Iberian Peninsula. Barcelona: SCEN-IEC.

VöLling, T. (1990): "Funditores im römischen Heer", Saalburg Jahrbuch, 45, pp. 24-58.

Wyttenbach, A. y Schubiger, P. A. (1973): "Trace element content of Roman lead by neutron activation analysis", Archaeometry, 15 (2), pp. 199-207. 